ORIGINAL ARTICLE

\title{
Ablation of neuropsin-neuregulin 1 signaling imbalances ErbB4 inhibitory networks and disrupts hippocampal gamma oscillation
}

\author{
M Kawata ${ }^{1,2}$, S Morikawa ${ }^{1,3}$, S Shiosaka ${ }^{1,4}$ and H Tamura ${ }^{3}$
}

Parvalbumin-expressing interneurons are pivotal for the processing of information in healthy brain, whereas the coordination of these functions is seriously disrupted in diseased brain. How these interneurons in the hippocampus participate in pathological functions remains unclear. We previously reported that neuregulin 1 (NRG1)-ErbB4 signaling, which is actuated by neuropsin, is important for coordinating brain plasticity. Neuropsin cleaves mature NRG1 (bound to extracellular glycosaminoglycans) in response to long-term potentiation or depression, liberating a soluble ligand that activates its receptor, ErbB4. Here, we show in mice that kainate-induced status epilepticus transiently elevates the proteolytic activity of neuropsin and stimulates cFos expression with a time course suggesting that activation of ErbB4- and parvalbumin-expressing interneurons follows the excitation and subsequent silencing of pyramidal neurons. In neuropsin-deficient mice, kainate administration impaired signaling and disrupted the neuronal excitation-inhibition balance (E/I balance) in hippocampal networks, by decreasing the activity of parvalbumin-positive interneurons while increasing that of pyramidal neurons, resulting in the progression of status epilepticus. Slow, but not fast, gamma oscillations in neuropsin-deficient mice showed reduced power. Intracerebroventricular infusion of the soluble NRG1 ligand moiety restored the E/I balance, status epilepticus and gamma oscillations to normal levels. These results suggest that the neuropsin-NRG1 signaling system has a role in pathological processes underlying temporal lobe epilepsy by regulating the activity of parvalbumin-expressing interneurons, and that neuropsin regulates E/I balance and gamma oscillations through NRG1-ErbB4 signaling toward parvalbumin-expressing interneurons. This neuronal system may be a useful target of pharmacological therapies against cognitive disorders.

Translational Psychiatry (2017) 7, e1052; doi:10.1038/tp.2017.20; published online 7 March 2017

\section{INTRODUCTION}

Cognition and its dysfunction are thought to depend on the coordinated excitation-inhibition (E/I) balance controlled by inhibitory inputs on the principal neurons in neural networks. ${ }^{1}$ Evidence suggests that parvalbumin-containing GABAergic inhibitory neurons are required for the synchronization of neural activities by oscillations in the hippocampus and cerebral cortex. ${ }^{2}$ In particular, parvalbumin-positive fast-spiking neurons, the major population of basket interneurons, coordinate the E/I balance and generate theta and gamma oscillations; ${ }^{3-6}$ both of these actions are involved in attention, memory and executive functions. ${ }^{7}$ Impairment of parvalbumin-expressing interneuron function leads to seizures ${ }^{8}$ and asynchronous network activity, ${ }^{3}$ thereby contributing to cognitive disturbance, which is the core feature of schizophrenia. ${ }^{9}$ As such, parvalbumin-expressing interneuron signaling is of utmost importance in cognitive brain functions based on the precise synchronization of neuronal ensembles. However, the mechanisms by which parvalbumin-expressing interneurons participate in active network communications are not well understood.
Limited proteolysis of trophic or signaling proteins at synapses induces plastic changes in neural function by irreversibly converting a precursor protein into a biologically active form. ${ }^{10}$ Because the activation of synaptic proteolysis largely depends on neural activity, extracellular proteases have distinct effects on activity-dependent neural events that underlie cognitive function. ${ }^{11-13}$ Indeed, recent studies showed that extracellular proteolysis has a critical role in dynamic synaptic remodeling, long-term potentiation, synaptic plasticity, memory formation and epileptogenesis. ${ }^{14-19}$

The hippocampus and amygdala, two brain regions that show a considerable degree of neural plasticity in the adult brain, express the extracellular serine protease neuropsin. ${ }^{20}$ Neuropsin is synthesized as a zymogen, which is then secreted and stored in the extracellular space in an inactive precursor form $^{21}$ that is transiently converted to an active form during neural activity; ${ }^{22}$ this then has a role in long-term potentiation, working memory, epileptogenic insult and anxiety. ${ }^{15,23,24}$ Because single nucleotide polymorphisms in the human neuropsin gene are associated with attention and concentration, verbal IQ disorders and bipolar

\footnotetext{
${ }^{1}$ Laboratory of Functional Neuroscience, Graduate School of Biological Sciences, Nara Institute of Science and Technology (NAIST), Nara, Japan; ${ }^{2}$ Department of Pharmacology,

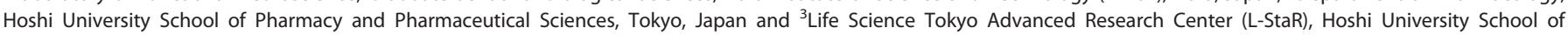

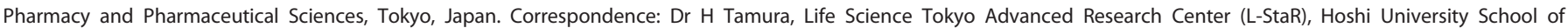
Pharmacy and Pharmaceutical Sciences, 2-4-41, Ebara, Shinagawa-ku, Tokyo 142-8501, Japan.

E-mail: h-tamura@hoshi.ac.jp

${ }^{4}$ Current address: Faculty of Health Science, Osaka Yukioka College of Health Science, 1-1-41 Sojiji, Ibaraki, Osaka 567-0801, Japan

Received 5 October 2015; revised 19 January 2017; accepted 25 January 2017
} 
disorder, ${ }^{25}$ neuropsin has recently garnered attention as an attractive target for therapeutic intervention.

We recently reported that, in the mouse hippocampus, neuropsin cleaves neuregulin 1 (NRG1) within a synaptic signaling system. $^{26}$ NGR1 is a neurotrophic factor belonging to the epidermal growth factor family and exists in six isoforms. ${ }^{27}$ Among these, type I, II and II are mainly expressed in the hippocampus of adult mice. ${ }^{28}$ They are transmembrane proteins and are cleaved by various proteases to release (except in the case of NRG1 type III) a soluble extracellular domain called mature NRG1 or mNRG1. ${ }^{27}$ In particular, owing to its heparin-binding domain, mNRG1 type $\mathrm{I}$ is confined to the glycosaminoglycan component of the extracellular matrix; however, upon processing by neuropsin it diffuses across the synapse and binds to its receptor, ErbB4. ${ }^{26}$ ErbB4 is expressed specifically by GABAergic neurons, particularly parvalbumin-expressing interneurons; ${ }^{29}$ thus proteolytic function of neuropsin is to specifically activate GABAergic neurons. Indeed, neuropsin-knockout (KO) mice show specific impairment of $\mathrm{GABA}_{\mathrm{A}}$ receptor-mediated transmission, which can be recovered by hippocampal application of a soluble form of NRG1 comprising its ligand domain. ${ }^{26}$ These findings strongly suggest that neuropsin regulates the activity of parvalbumin-positive GABAergic neurons, particularly ErbB4containing basket interneurons, via processing of mNRG1. Here, we examined the contribution of neuropsin-NRG1 signaling to the pathological functions of ErbB4-expressing, parvalbumin-positive GABAergic interneurons in the kainate (KA)-induced status epilepticus mouse model. We also examined whether neuropsin contributes to the E/I balance of local networks by counting the number of active pyramidal neurons and ErbB4-expressing parvalbumin-positive interneurons that were immunoreactive for c-Fos.

\section{MATERIALS AND METHODS}

Animals

A total of 261 adult male C57BL/6 J mice (aged 6-10 weeks; SLC, Hamamatsu, Japan) and 82 neuropsin-KO mice and corresponding 70 wildtype mice (aged 6-10 weeks) were used in this study. Neuropsin-KO mice were generated as previously described ${ }^{30}$ and backcrossed into the C57BL/ $6 \mathrm{~J}$ background for at least 20 generations. Animals were housed in cages with a $12 \mathrm{~h}$ light/dark cycle (lights on at 0800 hours) and given food and water ad libitum. All procedures conformed to the US National Research Council's Guide for the Care and Use of Laboratory Animals and were approved by the Nara Institute of Science and Technology's Animal Care and Use Committee. The procedures employed minimized animal suffering, and the lowest number of animals needed to produce the required results was used.

\section{Electrophysiology}

Mice were anesthetized with urethane $\left(1.25 \mathrm{~g} \mathrm{~kg}^{-1}\right.$; intraperitoneal (i.p.)) and placed in a stereotaxic frame (Narishige, Tokyo, Japan). A tungsten recording microelectrode (MicroProbes, Gaithersburg, MD, USA) was implanted into the right hippocampal CA1 pyramidal cell layer $(2.46 \mathrm{~mm}$ posterior to the bregma, $2 \mathrm{~mm}$ lateral to the midline and $1.20 \mathrm{~mm}$ ventral to the dural surface). To generate gamma oscillations, KA ( $25 \mathrm{mg} \mathrm{kg}^{-1}$; i.p.) was injected only once. The local field potential was recorded for at least $30 \mathrm{~min}$ before and $4 \mathrm{~h}$ after KA administration. The power spectra and integral power for the slow gamma $(30-50 \mathrm{~Hz})$ and the fast gamma $(65-$ $120 \mathrm{~Hz}$ ) range of the local field potential were calculated in $5 \mathrm{~min}$ segments across the recording using the fast Fourier transform algorithm in LabChart software (ADInstruments, Dunedin, New Zealand). The position of the recording site was verified histologically.

\section{KA administration and behavioral seizure scoring}

Status epilepticus was induced according to the method of Sperk et al. ${ }^{31}$ Briefly, mice received an i.p. injection of KA $\left(25 \mathrm{mg} \mathrm{kg}^{-1}\right.$; Enzo Life Sciences, Farmingdale, NY, USA) dissolved in phosphate-buffered saline, pH 7.4 (PBS; Nacalai Tesque, Kyoto, Japan), and were killed 1, 2, 3, 4, 6, 8 and $24 \mathrm{~h}$ later. Control animals received an equivalent volume of PBS. Seizure severity was scored on Racine's scale ${ }^{32}$ modified for mice, as follows: stage 0, normal activity; stage 1, immobility and staring; stage 2, forelimb or tail extension, rigid posture; stage 3, repetitive movements, head bobbing; stage 4, rearing and falling, hindlimb tonic-clonic movements; stage 5, continuous tonic-clonic seizures with running or jumping; and stage 6 , death. Only mice that displayed stage 4 or 5 seizure activity were used in this study unless otherwise specified. Additional low doses of KA $\left(10 \mathrm{mg} \mathrm{kg}^{-1}\right.$; i.p.) were administered to mice that did not exhibit a continuous motor seizure (stage 4 or 5 ) within $1 \mathrm{~h}$ of the first KA injection.

\section{Sample preparation}

Mice were killed by decapitation at various times after the administration of KA. Whole hippocampi were dissected on an ice-cold surface, frozen on dry ice and then stored at $-80^{\circ} \mathrm{C}$ until use. The hippocampal tissue was homogenized using 10 strokes of a glass-Teflon homogenizer (Taiyo, Osaka, Japan) with a motor-driven pestle.

Measurement of neuropsin protein and its proteolytic activity Measurement of the total amount and proteolytic activity of neuropsin was conducted as described previously. ${ }^{33,34}$ Briefly, hemi-hippocampal tissue from each mouse was homogenized in $0.75 \mathrm{ml}$ of lysis buffer $(50 \mathrm{~mm}$ HEPES, pH 7.5, $150 \mathrm{~mm} \mathrm{NaCl}, 5 \mathrm{~mm}$ EDTA, $1 \%$ Triton X-100 and $5 \mu \mathrm{g} \mathrm{ml}^{-1}$ leupeptin) and then centrifuged at $14000 \times g$ for $30 \mathrm{~min}$ at $4{ }^{\circ} \mathrm{C}$ to remove debris. The supernatant was incubated with the rat monoclonal antimouse neuropsin antibody mAbF12 (0.1 $\mu \mathrm{g}$; Molecular and Biological Laboratories, Nagoya, Japan) overnight at $4{ }^{\circ} \mathrm{C}$. The immunoprecipitated neuropsin was incubated with the synthetic fluorescent substrate Pro-PheArg-4-methyl-coumaryl-7-amide (Peptide Institute, Osaka, Japan) at $37^{\circ} \mathrm{C}$ for $18 \mathrm{~h}$. The product (7-amino-4-methylcoumarin) was quantified using a fluorescence spectrophotometer (F-4500; Hitachi, Tokyo, Japan). Neuropsin protease activity was calculated from a standard curve that was generated by serially diluting aliquots of recombinant neuropsin. ${ }^{21}$ Data were normalized to PBS-injected controls.

\section{Production of mNRG1-Fc protein}

A fragment of mouse $\mathrm{Nrg} 1$ type I encoding mNRG1 (ref. 26) was cloned into pFUSE-rlgG-Fc2 (IL2ss) (Nacalai Tesque) in frame with the Fc portion of the rabbit $\mathrm{lg}$. The fused mouse $\mathrm{mNrg} 1-\mathrm{Fc}$ gene was then inserted into pGEX-6P-1 (GE Healthcare Life Sciences, Tokyo, Japan). Recombinant glutathione-S-transferase-mouse-mNRG1-Fc was expressed in Escherichia coli and captured with glutathione Sepharose (GE Healthcare). Mouse mNRG1-Fc was eluted by cleavage of the glutathione-S-transferase tag with PreScission Protease (GE Healthcare). The correct sizes of mouse mNRG1-Fc and control Fc protein were verified by western blotting with a horseradish peroxidase (HRP)-conjugated donkey anti-Fc antibody (1:10 000, Jackson ImmunoResearch Laboratories, West Grove, PA, USA).

\section{Immunocytochemistry in MCF-7 cells}

Human breast cancer MCF-7 cells $\left(5 \times 10^{4}\right.$ cells per well; JCRB0134, JCRB Cell Bank, National Institutes of Biomedical Innovation, Health and Nutrition, Osaka, Japan) were plated in 24-well plates in high-glucose DMEM with L-glutamine (Sigma-Aldrich, St. Louis, MO, USA) supplemented with $10 \%$ fetal bovine serum, $100 \mathrm{U} \mathrm{ml}^{-1}$ penicillin and $100 \mathrm{\mu g} \mathrm{ml}^{-1}$ streptomycin at $37^{\circ} \mathrm{C}$ in $5 \% \mathrm{CO}_{2}$. The culture medium was changed to Opti-MEM (Life Technologies, Carlsbad, CA, USA) $24 \mathrm{~h}$ after seeding. An additional $24 \mathrm{~h}$ later, cells were treated with $\mathrm{Fc}$ protein or mouse mNRG1Fc with or without $10 \mathrm{mg} \mathrm{m}^{-1}$ heparin (Sigma-Aldrich) or neuropsin $\left(10 \mathrm{mU} \mathrm{ml}^{-1}\right)$ in the culture medium for $60 \mathrm{~min}$, washed and then incubated with an Alexa 488-conjugated donkey anti-rabbit lgG in fresh Opti-MEM (A21206; 1:1000, Molecular Probes, Eugene, OR, USA) for $1.5 \mathrm{~h}$ at room temperature. The cells were mounted in ProLong Diamond with DAPI (Life Technologies). Images were captured using a Zeiss LSM710 confocal laser-scanning microscope (Carl Zeiss Microlmaging, Jena, Germany). Fluorescence intensity was measured with ImageJ software (version 1.48; National Institutes of Health, Bethesda, MD, USA).

\section{Cleavage of mNRG1 by neuropsin}

Recombinant human mNRG1 type I (amino acids 2-246; R\&D Systems, Minneapolis, MN, USA) was incubated with neuropsin $\left(10 \mathrm{mU} \mathrm{ml}^{-1}\right)$ at $37^{\circ}$ $\mathrm{C}$ for $60 \mathrm{~min}$ in reaction buffer $(50 \mathrm{~mm}$ Tris- $\mathrm{HCl}, \mathrm{pH} 8$ and $0.5 \mathrm{~mm} \mathrm{CaCl}$ ). 
Cleaved human mNRG1 was separated on 15\% SDS-PAGE gels and immunoblotted with a rabbit polyclonal anti-C-terminal mNRG1 antibody (H-210; 1:400, Santa Cruz Biotechnology, Dallas, TX, USA). The blots were developed with an HRP-conjugated donkey anti-rabbit IgG antibody (1:10,000, Jackson ImmunoResearch Laboratories) and chemiluminescent (Immobilon Western; Millipore, Billerica, MA, USA).

\section{mNRG1-induced receptor phosphorylation assay}

The receptor phosphorylation assay was performed as previously described. ${ }^{26}$ Neuropsin $\left(10 \mathrm{mU} \mathrm{ml}{ }^{-1}\right)$ or vehicle was incubated with 0-16 nm human mNRG 1 at $37^{\circ} \mathrm{C}$ for 60 min and then the mixture applied to MCF-7 cells. After $20 \mathrm{~min}$, cells were lysed with lysis buffer $(50 \mathrm{~mm}$ HEPES, pH 7.5, $150 \mathrm{~mm} \mathrm{NaCl}, 1 \%$ Triton X-100, 1\% CHAPS, $5 \mathrm{~mm}$ EDTA, $50 \mathrm{~mm}$ sodium fluoride, $1 \mathrm{~mm}$ PMSF, $10 \mathrm{~mm}$ sodium pyrophosphate, $1 \mathrm{~mm}$ sodium orthovanadate and $1 \%$ protease inhibitor cocktail (P8340; SigmaAldrich)). The lysates were centrifuged at $14000 \times g$ for $10 \mathrm{~min}$. Protein concentrations in the supernatants were determined with a BCA protein assay kit (Thermo Fisher Scientific, Waltham, MA, USA), and equal amounts of total protein were subjected to $7.5 \%$ SDS-PAGE and transferred to nitrocellulose membranes (Bio-Rad Laboratories, Hercules, CA, USA). Membranes were blocked with $5 \%$ skimmed milk prepared in Tris-buffered saline containing $0.1 \%$ Tween- 20 for $30 \mathrm{~min}$. Next, the membranes were probed with a mouse monoclonal anti-phosphotyrosine antibody (4G10; 1:1,000, Millipore) and an HRP-conjugated mouse monoclonal anti- $\beta$-actin antibody (ab20272; 1:40 000, Abcam, Cambridge, UK) overnight at $4{ }^{\circ} \mathrm{C}$, followed by a second incubation with an HRP-conjugated donkey antirabbit IgG antibody (1:10 000, Jackson ImmunoResearch Laboratories) for $1 \mathrm{~h}$ at room temperature. After incubation with a chemiluminescent reagent (Immobilon Western; Millipore), the membranes were exposed to X-ray films (Fujifilm, Tokyo, Japan).

\section{Quantitative real-time PCR}

Total RNA was extracted from hippocampi using TRlzol reagent (Life Technologies) according to the manufacturer's instructions. For cDNA synthesis, total RNA $(0.5 \mu \mathrm{g})$ was reverse transcribed with TaqMan reverse transcription reagents using random hexamers (Life Technologies). Quantitative real-time PCR was conducted using a LightCycler Instrument (Roche Diagnostics, Basel, Switzerland) with SYBR Green PCR Master Mix (Roche Applied Science, Upper Bavaria, Germany). Following denaturation for $10 \mathrm{~min}$ at $95^{\circ} \mathrm{C}$, the reactions were cycled 40 times with denaturation at $95^{\circ} \mathrm{C}$ for $10 \mathrm{~s}$, annealing at $60^{\circ} \mathrm{C}$ for $10 \mathrm{~s}$ and elongation at $72{ }^{\circ} \mathrm{C}$ for $14 \mathrm{~s}$. The following primers were used to amplify specific CDNA regions of interest: Nrg1 type I (sense, 5'-ATGTCTGAGCGCAAAGAAGG-3'; antisense, 5'-CTCCTGGCTITCATCTCTITCA-3'), neuropsin gene Klk8 (sense, 5'-CCCA CTGCAAAAAACAGAAG-3'; antisense, 5'-TGTCAGCTCCATTGCTGCT-3') and Gapdh (sense, 5'-CGGGAAGCCCATCACCATC-3'; antisense, 5'-GAGGGGCC ATCCACAGTCTT-3').

\section{NRG1 ELISA}

NRG1 protein levels were measured using a commercial sandwich ELISA kit according to the manufacturer's instructions (Uscn Life Science, Hubei, People's Republic of China). Briefly, the hippocampal tissues were homogenized in a motor-driven glass-Teflon homogenizer with PBS containing $1 \%$ Triton X-100 and $1 \%$ protease inhibitor cocktail, followed by centrifugation at $14000 \times g$ for $10 \mathrm{~min}$ at $4{ }^{\circ} \mathrm{C}$. The supernatants were collected and aliquoted into 96-well plates pre-coated with an antibody specific to NRG1, and the plate was incubated for $2 \mathrm{~h}$ at $37^{\circ} \mathrm{C}$. A biotinconjugated antibody specific to NRG1 was added and incubated, followed by the addition of avidin-conjugated HRP. Tetramethylbenzidine was used as the chromogenic substrate. The optical density was read with a microplate reader at $450 \mathrm{~nm}$ (Bio-Rad Laboratories), and the concentrations of NRG1 were calculated from a standard curve of purified NRG1 provided with the kit.

\section{Western blot analysis}

Mice were killed by decapitation, and the hippocampal region was rapidly dissected. The tissue was suspended in ice-cold isotonic sucrose buffer ( $50 \mathrm{~mm}$ HEPES, pH 7.5, $0.32 \mathrm{~m}$ sucrose, $5 \mathrm{~mm}$ EDTA, $1 \mathrm{~mm}$ sodium fluoride, $1 \mathrm{~mm}$ sodium orthovanadate, and $1 \%$ protease inhibitor cocktail) and homogenized on ice in a glass-Teflon homogenizer. Subsequent procedures were performed at $4{ }^{\circ} \mathrm{C}$. Homogenates were centrifuged at $1000 \times g$ for $5 \mathrm{~min}$ to remove nuclei. The supernatants were centrifuged again at
$10000 \times g$ for $20 \mathrm{~min}$ to pellet the crude membrane fraction. The obtained membrane preparations were lysed in lysis buffer $(5 \mathrm{~mm}$ HEPES, pH 7.5, $150 \mathrm{~mm} \mathrm{NaCl}, 5 \mathrm{~mm}$ EDTA, 1\% SDS, $1 \mathrm{~mm}$ sodium fluoride, $1 \mathrm{~mm}$ sodium orthovanadate, and $1 \%$ protease inhibitor cocktail), and the lysates were centrifuged at $14000 \times g$ to remove debris. The protein concentrations of the supernatants were determined with a BCA protein assay kit (Thermo Fisher Scientific), and equal amounts of total protein were separated on $7.5 \%$ SDS-PAGE gels. Following transfer to nitrocellulose membranes (Bio-Rad Laboratories), free protein-binding sites were blocked with $5 \%$ skimmed milk prepared in Tris-buffered saline containing 0.1\% Tween-20 for $30 \mathrm{~min}$. The membranes were incubated with rabbit monoclonal antiphospho-ErbB4 (Y1284) (21A9; 1:1,000, Cell Signaling Technology, Danvers, MA, USA) and HRP-conjugated mouse monoclonal anti- $\beta$-actin (ab20272; 1:40 000, Abcam) antibodies overnight at $4{ }^{\circ} \mathrm{C}$. Subsequently, the blots were developed using an HRP-conjugated donkey anti-rabbit lgG antibody (1:10 000, Jackson ImmunoResearch Laboratories) and the chemiluminescent reagent (Immobilon Western; Millipore), and exposed to X-ray films (Fujifilm). The blots were stripped and hybridized with a rabbit polyclonal anti-C-terminal ErbB4 antibody (C-18) (sc-283; 1:600, Santa Cruz Biotechnology) to determine the total amount of ErbB4. Band densities were quantified with ImageJ software. The staining of $\beta$-actin was used as a standard for protein quantification.

\section{Immunohistochemical analysis of hippocampal tissue}

Mice were anesthetized with urethane $\left(1.25 \mathrm{~g} \mathrm{~kg}^{-1}\right.$; i.p.) 1 or $4 \mathrm{~h}$ after KA administration. They were transcardially perfused with $0.85 \%$ sterile saline and then with $4 \%$ paraformaldehyde prepared in PBS, followed by postfixation overnight at $4{ }^{\circ} \mathrm{C}$. The brains were cryoprotected in $30 \%$ sucrose solution at $4{ }^{\circ} \mathrm{C}$ for $48 \mathrm{~h}$ and then sectioned coronally at a thickness of $30 \mu \mathrm{m}$ using a sliding microtome. After blocking with 5\% BSA prepared in PBS for $1 \mathrm{~h}$, the sections were incubated overnight at $4{ }^{\circ} \mathrm{C}$ with the following antibodies: rabbit polyclonal anti-cFos (AB-5; 1:5000, Millipore), goat polyclonal anti-cFos (sc-52-G; 1:1000, Santa Cruz Biotechnology), a rabbit polyclonal anti-C-terminal ErbB4 antibody (C-18) (sc-283; 1:100, Santa Cruz Biotechnology), mouse monoclonal anti-ErbB4 (Ab77) (H4.77.16; 1:100, Novus Biologicals, Littleton, CO, USA), mouse monoclonal anti-CAMKII (Clone 6G9; 1:100, Millipore), rabbit polyclonal antiparvalbumin (ab11427; 1:3000, Abcam) and mouse monoclonal antiparvalbumin (P3088; 1:3000, Sigma-Aldrich). The following secondary antibodies used in the study were all purchased from Thermo Fisher Scientific: Alexa 488-conjugated donkey anti-mouse lgG (1:1000; A21203), Alexa 488-conjugated donkey anti-rabbit IgG (1:1000; A21206), Alexa 594-conjugated donkey anti-mouse IgG (1:1000; A21203), Alexa 594conjugated donkey anti-rabbit lgG (1:1000; A21207), Alexa 594-conjugated donkey anti-goat IgG (1:1000; A11058), Alexa 647-conjugated donkey anti-mouse IgG (1:1000; A31571), Alexa 647-conjugated donkey anti-rabbit IgG (1:1000; A31573), and Alexa 647-conjugated donkey anti-goat IgG (1:1000; A21447). Nuclei were labeled with Hoechst 33342 dye (Dojindo Laboratories, Kumamoto, Japan). Stained sections were mounted using Prolong Gold antifade reagent (Life Technologies).

\section{Cell counting analysis}

Six sequential sections were imaged at $2 \mu \mathrm{m}$ intervals along the $z$-axis using a Zeiss confocal microscope fitted with a $\times 20$ objective lens. The cFos-, ErbB4- and parvalbumin-positive cells (that is, cells showing fluorescence intensity above background) in the hippocampal CA1 region were estimated by disector-based cell counting method using ImageJ software as described earlier. ${ }^{35}$ The pairs of parallel sections were set and only neurons that appear in one of the two sections (reference section) and not in the other (look-up section) were counted (Supplementary Figure 1). The average value per unit area $\left(500000 \mu^{3}\right)$ in five slices from each animal was calculated. To avoid any bias, stereological examination was performed by an investigator blinded to the genotype. The fraction of pyramidal neurons, ErbB4-positive neurons, and parvalbumin-positive interneurons expressing cFos was then calculated. The E/l balance was defined as the ratio between the fraction of cFos-expressing pyramidal neurons and either c-Fos-expressing ErbB4-positive neurons or CFosexpressing parvalbumin-positive interneurons.

\section{Intracerebroventricular NRG1 injection procedures}

Mice were anesthetized with urethane $\left(1.25 \mathrm{~g} \mathrm{~kg}^{-1}\right.$; i.p.) or isoflurane $(2 \%$; Wako Pure Chemical Industries, Tokyo, Japan) and placed in a stereotaxic frame. In electrophysiological experiments, stainless-steel cannulae 
(Plastics One, Roanoke, VA, USA) were implanted stereotaxically into the lateral ventricle $(0.22 \mathrm{~mm}$ posterior to the bregma, $1 \mathrm{~mm}$ lateral to the midline and $2 \mathrm{~mm}$ ventral to the dural surface). To analyze the effect of NRG1 177-246 infusion on the seizure score and cFos expression after KA administration, stainless-steel guide cannulae (Plastics One) were placed above the lateral ventricle and secured in the skull using dental cement. Dummy cannulae (Plastics One) were then inserted into the guide cannulae and replaced 1 week later with the injection cannulae, which projected $0.5 \mathrm{~mm}$ below the tip of the guide cannulae. Recombinant human epidermal growth factor-like domain of NRG1 (5 $\mu \mathrm{m}$ in PBS; NRG 1 177-246; PeproTech, Rocky Hill, NJ, USA) or vehicle was delivered either $10 \mathrm{~min}$ or $3 \mathrm{~h}$ after $\mathrm{KA}$ administration via a Hamilton syringe mounted on an infusion pump (CFV-2100; Nihon Koden, Tokyo, Japan) at a flow rate of $0.2 \mu \mathrm{min}^{-1}$ for $10 \mathrm{~min}$. Control infusions used only PBS.

\section{Statistical analysis}

All data are expressed as the mean and standard error of the mean (SEM). Statistical significance was determined as indicated by applying a twotailed unpaired Student's $t$-test (normal distribution), the Mann-Whitney $U$ test (non-normal distribution), one-way ANOVA with Tukey's or Dunnett's post-hoc test, or two-way ANOVA with the Sidak post-hoc test (comparison of multiple groups). No statistical methods were used to predetermine sample sizes, but the sample sizes used are similar to those reported in previous publications. ${ }^{18,36}$ The criterion for statistical significance was $P<0.05$.

\section{RESULTS}

Neuropsin is activated during KA-evoked seizures

To investigate whether hippocampal neuropsin activity is affected by seizures, we used an animal model of temporal lobe epilepsy. A microelectrode was inserted into the CA1 pyramidal cell layer of C57BL/ $6 \mathrm{~J}$ mice to measure neural activity, and behavioral seizures were induced by i.p. injection of KA. KA administration induced an epileptic discharge accompanied by generalized tonic-clonic behavioral seizures (Figures $1 \mathrm{a}$ and $\mathrm{b}$ ). Although spiking rates and burst amplitudes peaked at about $2 \mathrm{~h}$ and $2.5 \mathrm{~h}$, respectively, neuropsin activity peaked at $4 \mathrm{~h}$ (one-way ANOVA, $\mathrm{F}_{(7,44)}=7.902$, $P<0.0001$ vs PBS-treated mice; Figure 1c, left). Neuropsin activity remained significantly elevated at $6 \mathrm{~h}$ (one-way ANOVA, $P<0.0001$ vs PBS-treated mice) before finally returning to control levels (Figure 1c, left). No change in neuropsin activity was detected in mice that did not develop status epilepticus after several injections of KA, $\left(t\right.$-test, $t_{14}=0.3421, P=0.7373$; Figure $1 c$, right). Neuropsin mRNA expression remained unchanged or decreased slightly (but not significantly) both during and after seizures (one-way ANOVA, $F_{(7,30)}=1.597, P=0.1746$; Figure $1 d$ ), and the amount of neuropsin protein in the hippocampus of mice injected with KA $\left(1.825 \pm 0.075 \mathrm{ng} \mathrm{mg}^{-1}\right.$ protein) was slightly, but significantly, lower than that of controls (PBS: $2.028 \pm 0.032$ $\mathrm{ng} \mathrm{mg}^{-1}$ protein; $t$-test, $t_{8}=2.471, P=0.0386$; Figure $\left.1 \mathrm{e}\right)$. These results indicate that the proteolytic activity of neuropsin is enhanced by KA-induced seizures without any increase in transcription and translation; a finding consistent with that of a previous study. ${ }^{22}$

Neuropsin contributes to KA-induced status epilepticus

Because neuropsin activity was upregulated 4 and $6 \mathrm{~h}$ after KA injection, we examined whether neuropsin contributes to KAinduced status epilepticus using neuropsin-KO mice at these time points. Although we observed no significant differences in the total KA dose required to obtain a continuous motor seizure ( $t$ test, $t_{20}=0.3043, P=0.7641$ ) and onset of status epilepticus ( $t$-test, $\left.t_{20}=0.1743, P=0.8634\right)$ between wild-type and neuropsin-KO mice (Supplementary Table 1), the severity of the seizures in neuropsin-KO mice after KA injection was significantly greater than that in wild-type mice only at the $4 \mathrm{~h}$ time point ( $n=11$ mice, two-way ANOVA, $\mathrm{F}_{(1,20)}=5.744, P=0.046$; Figure 2). Neuropsin-KO mice tended to exhibited stage 4 or 5 behavior for longer than wild-type mice, although the difference was not statistically significant (neuropsin-KO, $110.9 \pm 7.9 \mathrm{~min}, n=11$; wild-type, $83.1 \pm 12.4 \mathrm{~min}, n=11 ; t$-test, $\left.t_{20}=1.886, P=0.074\right)$. These data indicate that deleting neuropsin leads to progression of KAinduced status epilepticus.

Neuropsin liberates the ligand moiety of mNRG1 from heparan sulfate proteoglycans

To analyze the role of neuropsin during proteolysis of natural substrates, we examined the processing of mNRG1, the native substrate of neuropsin, ${ }^{26}$ in MCF-7 cells (which express abundant amounts of ErbB receptors, including ErbB4). ${ }^{37}$ We first generated a recombinant chimeric protein, called mouse mNRG1-Fc, comprising the extracellular domain of mouse NRG1 fused to the Fc portion of rabbit lg (Figure 3a) and bath-applied it to MCF-7 cells. Strong immunoreactive signals for mouse mNRG1-Fc, but not the Fc control protein, were observed on MCF-7 cells (one-way ANOVA, $P<0.0001$ vs Fc; Figures $3 \mathrm{~b}$ and $\mathrm{c}$ ), indicating cell-surface binding. Co-incubation in the presence of the heparan sulfate analog, heparin or neuropsin reduced the mouse mNRG1-Fc immunoreactivity (one-way ANOVA, $P<0.0001$ vs vehicle; Figures $3 \mathrm{~b}$ and $\mathrm{c}$ ), suggesting that $\mathrm{mNRG1}$ was released from heparan sulfate proteoglycans (HSPGs) by neuropsin-mediated proteolytic cleavage. As HSPG-bound mNRG1 does not induce phosphorylation of its receptor (ErbB) in cells, ${ }^{38}$ we hypothesized that it must be processed by neuropsin for this effect to take place. To test this, we investigated the tyrosine phosphorylation status of ErbB in MCF-7 cells incubated with different concentrations of recombinant human mNRG1 in the presence or absence of neuropsin. As shown in Figures $3 \mathrm{~d}$ and e, neuropsin cleaved human mNRG1 at multiple sites to yield two major bands corresponding to the cleaved mNRG1 C-terminal fragments shown previously; ${ }^{26}$ it also increased phosphorylation of ErbB in the presence of very low concentrations of human mNRG1 (2$16 \mathrm{~nm})$. At high concentrations $(16 \mathrm{~nm})$, a small proportion of mNRG1 was not inhibited by HSPGs, even in the absence of neuropsin, presumably due to saturation of mNRG1 binding sites on HSPGs. Taken together, these results suggest that neuropsin activates and enhances NRG1 signaling.

NRG1-ErbB4 signaling is actuated by neuropsin in the epileptic hippocampus

Because cleavage by neuropsin and the subsequent release of the ligand moiety of NRG1 are necessary for the activation of ErbB4, we hypothesized that neuropsin, when activated by epileptic seizures, stimulates NRG1-ErbB4 signaling in vivo. Four to six hours after KA administration, when neuropsin was highly activated (Figure 1c), Nrg1 type I mRNA expression and ErbB4 phosphorylation levels were simultaneously increased in mouse hippocampi (Supplementary Figure 2). Hence, we examined whether neuropsin-KO mice exhibit abnormal NRG1-ErbB4 signaling during seizures. At $4 \mathrm{~h}$ post-KA injection, Nrg1 type I mRNA expression in neuropsin-KO mice increased to the same extent as that in wild-type mice (one-way ANOVA, $P=0.9889$; Figure 3f); however, ELISA revealed that 'basal' levels of NRG1 (in $\mathrm{PBS}$-injected animals) were higher in $\mathrm{KO}$ than in wild-type mice (one-way ANOVA, $P=0.0017$ vs PBS-injected wild-type mice) and that the amount of NRG1 protein after KA administration was also greater in KO than in wild-type mice (one-way ANOVA, $P=0.0004$ vs KA-injected wild-type mice; Figure $3 \mathrm{~g}$ ), indicating that much of the NRG1 protein in neuropsin-KO mice remains bound to HSPGs. Moreover, western blotting showed that phosphorylated ErbB4 protein levels in the hippocampi of wild-type mice at $4 \mathrm{~h}$ after KA injection increased significantly (one-way ANOVA, $F_{(3,22)}=9.601$, $P=0.0003$ vs $P B S)$; this was not the case in neuropsin-KO mice (one-way ANOVA, $P=0.9637$ vs PBS; Figures $3 \mathrm{~h}$ and i). On the other hand, the total amount of ErbB4 protein did not change 
a

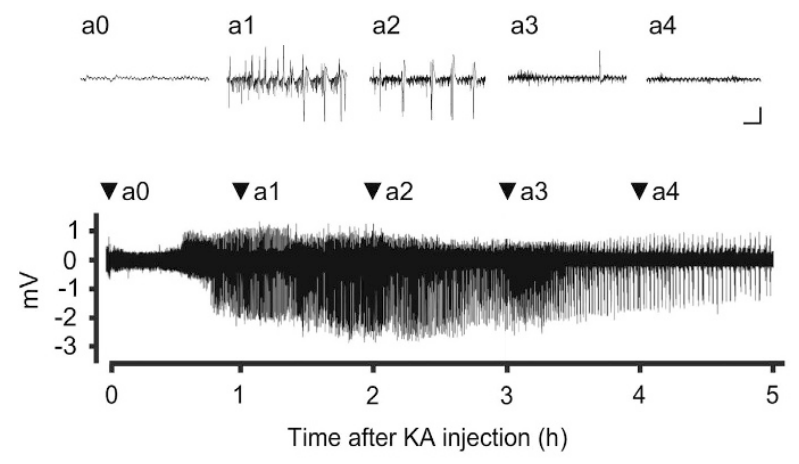

b

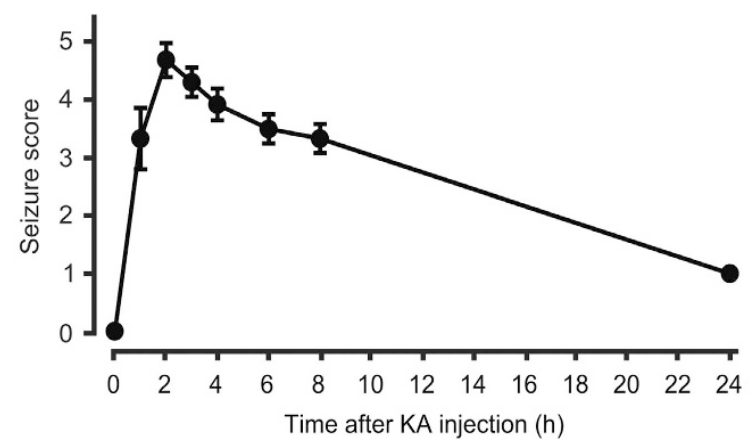

\section{C}

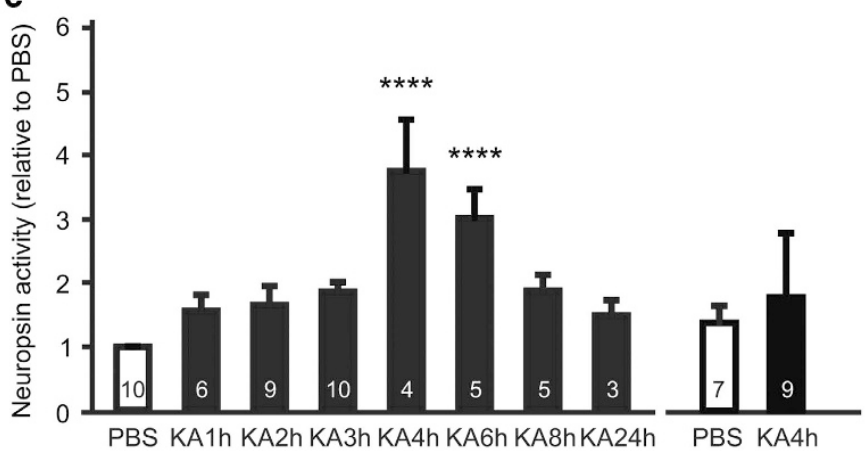

d
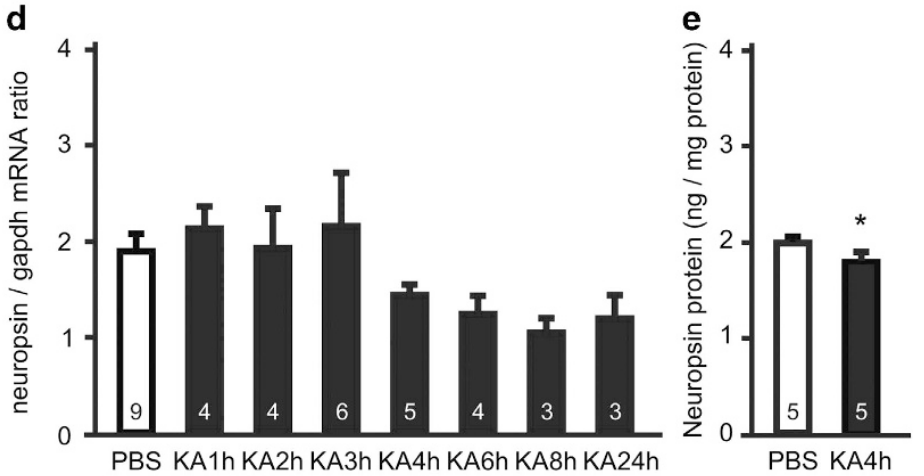

Figure 1. Seizures activate hippocampal neuropsin in vivo. (a) Representative trace of a local field potential in the hippocampal CA1 region after intraperitoneal injection of kainate (kainic acid, KA). Insets (a0-a4) show the waveforms at the times indicated by arrowheads. Scale bars, $1 \mathrm{mV}$ and $1 \mathrm{~s}$. (b) Time course for the change in seizure scores after KA administration. The seizure score increased sharply within $1 \mathrm{~h}$ after KA administration and remained high for at least $8 \mathrm{~h}(n=13$ mice). (c) Endogenous neuropsin activity at various time points in the hippocampus of mice in which status epilepticus was induced (left) or not induced (right) by KA administration. Neuropsin activity was significantly higher 4 and $6 \mathrm{~h}$ after $\mathrm{KA}$ administration only in those mice with induced status epilepticus $\left(\mathrm{F}_{(7,44)}=7.902 ; * * * * P<0.0001\right.$, one-way ANOVA with Dunnett's post-hoc test). (d) Quantitative real-time PCR analysis of neuropsin mRNA in mouse hippocampus after KA administration. Data are shown as neuropsin mRNA relative to Gapdh mRNA. The expression of neuropsin mRNA was not affected by seizure activity (one-way ANOVA, $\left.\mathrm{F}_{(7,30)}=1.597, P=0.1746\right)$. (e) Concentration of neuropsin protein in the mouse hippocampus $4 \mathrm{~h}$ after PBS (white bars) or KA (black bars) administration. The amount of neuropsin protein fell slightly at $4 \mathrm{~h}$ after KA administration ( $t$-test, $t_{8}=2.471 ;{ }^{*} P=0.0386$ vs PBS-treated mice). Error bars indicate the SEM. Numbers inside columns indicate $n$. PBS, phosphate buffered saline; SEM, standard error of the mean.

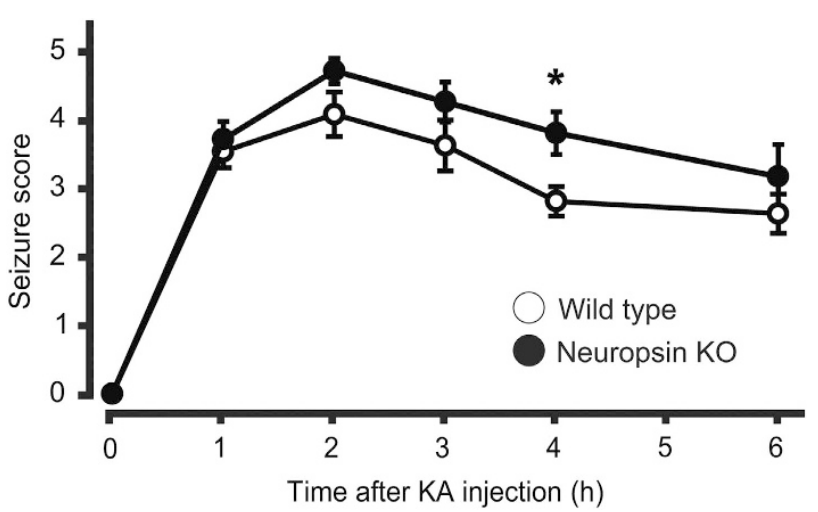

Figure 2. Time course for the seizure score in neuropsin-knockout (KO) mice administered kainate (KA). Mice received repeated injections of KA. KA-treated neuropsin-KO mice (black circles; $n=11$ mice) showed progression of seizures compared with KAtreated wild-type mice (white circles; $n=11$ mice, two-way ANOVA, $\left.\mathrm{F}_{(1,20)}=5.744 ;{ }^{*} P=0.0264\right)$. Seizure score of neuropsin-KO mice was significantly higher than that of wild-type mice only at the $4 \mathrm{~h}$ after KA administration ( ${ }^{*} P=0.046$; two-way ANOVA with the Sidak posthoc test). Error bars indicate standard error of the mean. significantly in either group, even after KA administration (oneway ANOVA, $\mathrm{F}_{(3,22)}=2.855, P=0.0604$; Figures $3 \mathrm{~h}$ and i). Taken together, these data suggest that processing of NRG1 by neuropsin is critical for induction of NRG1-ErbB4 signaling in vivo.

Significant decrease of seizure-related cFos expression in parvalbumin-expressing interneurons of neuropsin-KO mice

Because NRG1 is known to regulate the excitability of parvalbumin-expressing interneurons expressing ErbB4, ${ }^{39}$ it was important to examine whether neuropsin also contributed to GABAergic cellular activity in vivo. Therefore, we assessed the activation of ErbB4-expressing neurons in the hippocampal CA1 region after $\mathrm{KA}$ administration using cFos immunoreactivity as a marker for neuronal activity. Although no cFos expression was detected in the CA1 region of PBS-injected control mice, an abundance of cFos-labeled pyramidal neurons was observed at $1 \mathrm{~h}$ post-KA administration $(249.6 \pm 14.4$ neurons per area; Supplementary Figure 2); however, a few ErbB4-positive neurons showed very slight cFos immunoreactivity $(1.9 \pm 0.6$ neurons per area; Supplementary Figure 3). At $4 \mathrm{~h}$ after KA administration, the number of cFos-labeled pyramidal neurons decreased significantly $(30.0 \pm 3.4$ neurons per area; Mann-Whitney $U$ test, $P=0.0286$ vs 
a

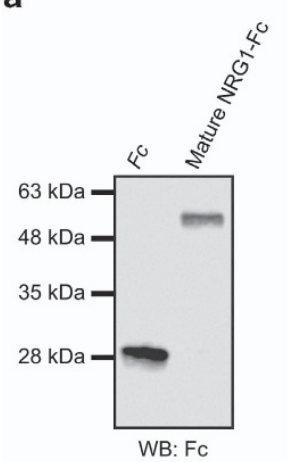

C

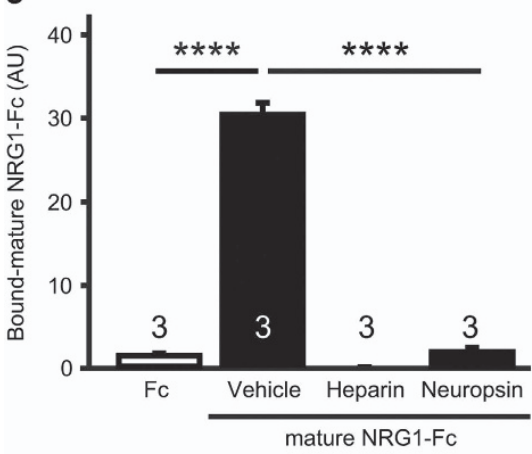

f

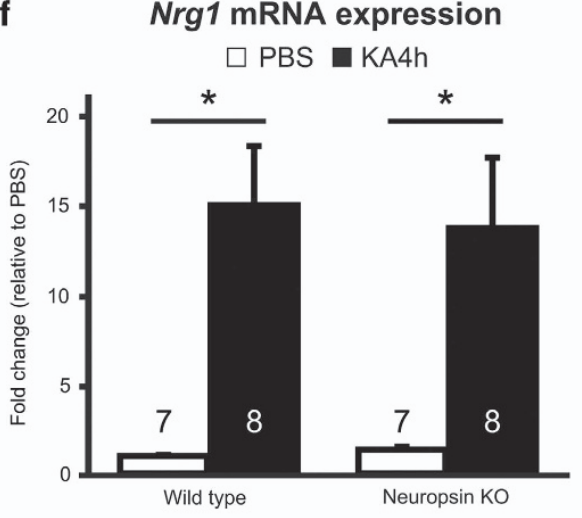

h

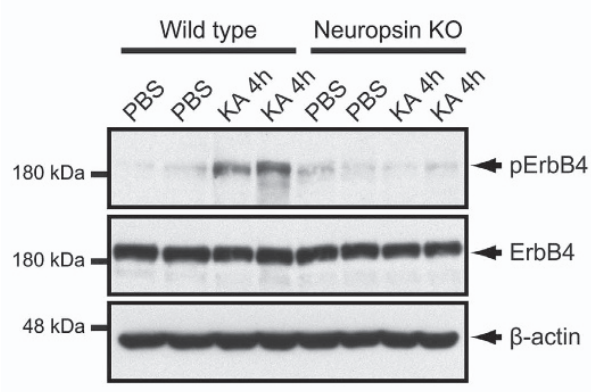

b
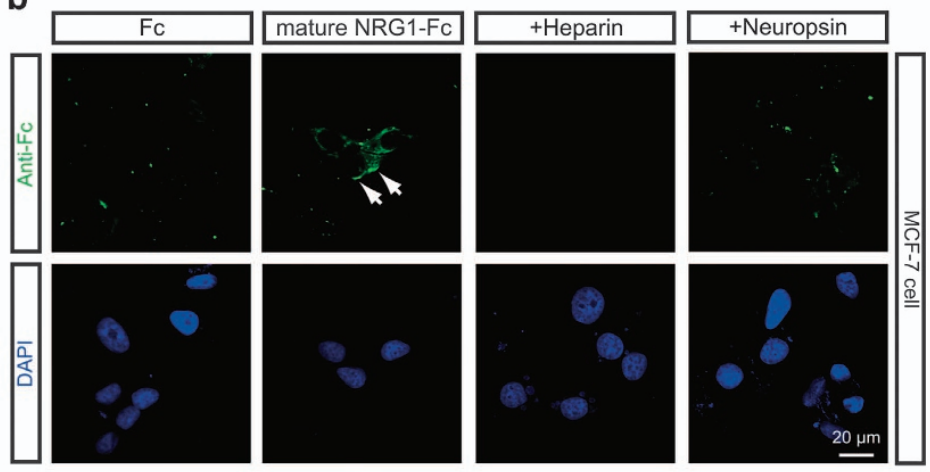

e

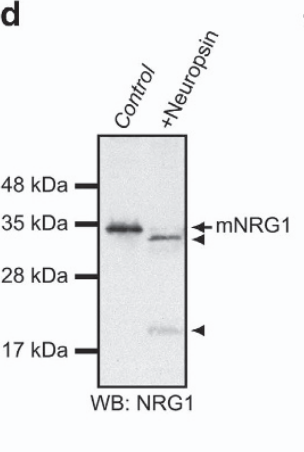

g
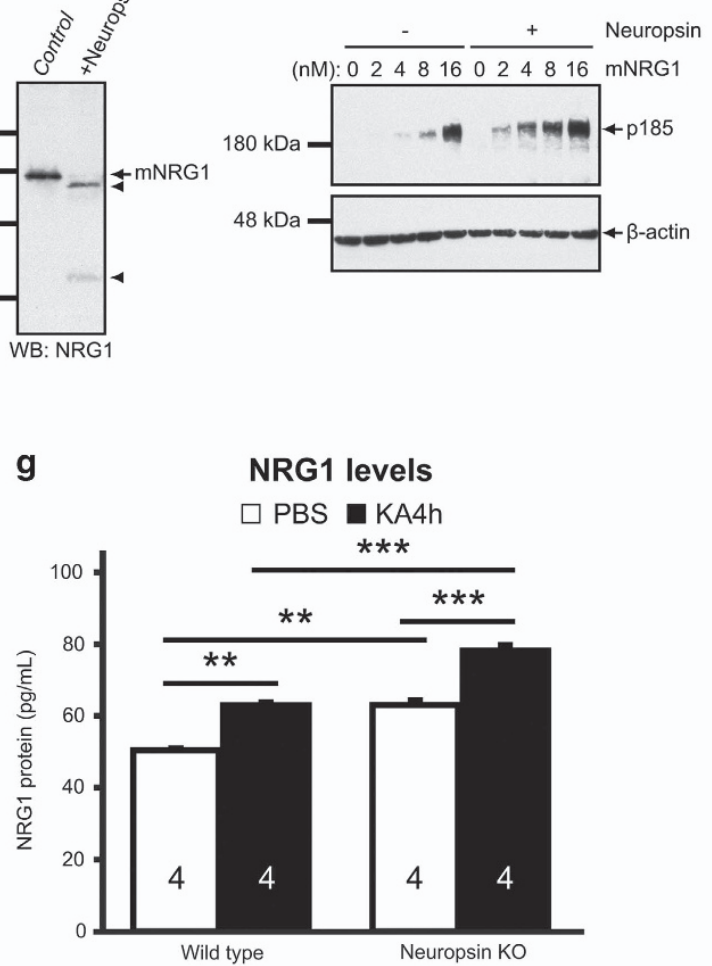

i

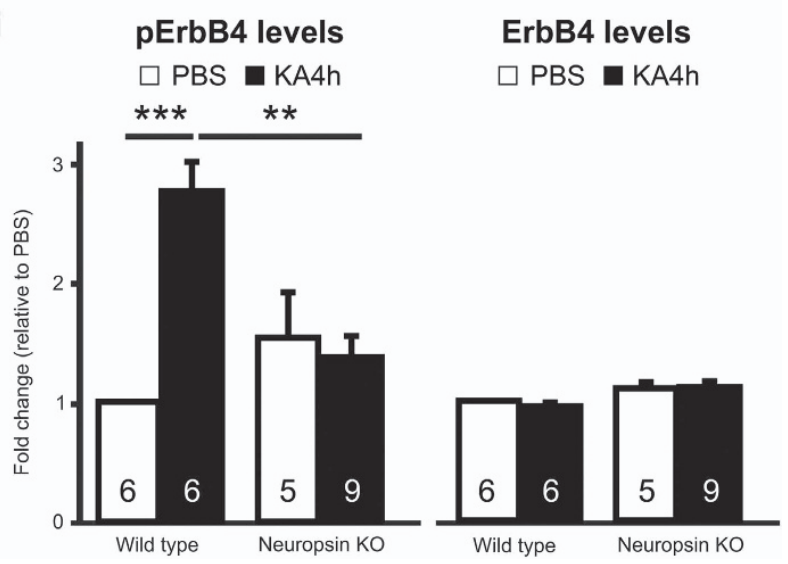

$1 \mathrm{~h}$ after KA administration; Supplementary Figure 3) and in parallel with a reduction in local field potential activity (Figure 1a). Nevertheless, strong cFos immunoreactivity was observed in most ErbB4-labeled neurons (17.6 \pm 1.7 neurons per area;

Mann-Whitney $U$ test, $P=0.0286$ vs $1 \mathrm{~h}$ after KA administration; Supplementary Figures 3 and 4). ErbB4-labeled neurons exhibiting strong cFos immunoreactivity were positive for parvalbumin, but not for calcium/calmodulin-dependent protein kinase (CAMKII), a 
Figure 3. Neuropsin modulates NRG1-ErbB4 signaling. (a) Western blots with control Fc protein and mouse mNRG1-Fc protein probed with an anti-Fc antibody. (b) MCF-7 cells were treated with mNRG1-Fc with or without heparin or neuropsin. Fc and mNRG1-Fc were detected with Alexa Fluor 488-conjugated anti-rabbit lgG (green, upper panels). The nuclei were labeled with DAPI (blue, lower panels). mNRG1-Fc binds to MCF-7 cells, and this binding is abolished by treatment of the cells with heparin or neuropsin. (a, b) Each show one representative result from three independent experiments. (c) Quantitative analysis of Fc (white bar) or mNRG1-Fc (black bars) immunofluorescent staining in MCF-7 cells after treatment with vehicle, heparin or neuropsin (30-54 cells; $n=3$ independent experiments) as shown in b. Heparin or neuropsin administration significantly reduced the immunoreactivity of mNRG1-Fc (one-way ANOVA, $\mathrm{F}_{(3,8)}=247.0$; $* * * P<0.0001$ vs vehicle). Means (AU, arbitrary units) and the SEM are shown. ${ }^{* * * P}<0.0001$; one-way ANOVA with Tukey's post-hoc test. (d) Recombinant human mNRG1 was preincubated without (Control) or with neuropsin (+Neuropsin) and then subjected to western blotting with an anti-C-terminal mNRG1 antibody. Proteolytic cleavage of mNRG1 by neuropsin results in the appearance of two major immunoreactive fragments (arrowheads), corresponding to cleaved mNRG1 C-terminal fragments. Similar results were seen in three independent experiments. (e) MCF-7 cells were treated with human mNRG1 at the indicated concentrations with or without neuropsin. Phosphorylation of p185 (ErbB), the receptor for mNRG1, was analyzed by western blotting with an anti-phosphotyrosine antibody. The $\beta$-actin control blot verified equivalent loading. Similar results were obtained in three independent experiments. (f) Nrg1 type I mRNA levels are upregulated in the hippocampus of both wild-type $\left({ }^{*} P=0.0126\right.$ vs PBS) and neuropsin-KO ( ${ }^{*} P=0.0312$ vs PBS) mice $4 \mathrm{~h}$ after KA administration (black bars) compared with those following PBS injection (white bars) (one-way ANOVA, $\left.\mathrm{F}_{(3,26)}=6.654 ; P=0.0017\right)$. Nrg1 type I mRNA was quantified relative to the expression of Gapdh mRNA using real-time PCR. The fold change was normalized to PBS in wild-type mice. (g) Concentration of NRG1 protein, measured using ELISA, in hippocampal homogenates from wild-type or neuropsin-KO mice $4 \mathrm{~h}$ after PBS (white bars) or KA (black bars) administration. KA-induced upregulation of NRG1 protein levels in neuropsin-KO mice is greater than that in wild-type mice (one-way $A N O V A, F_{(3,12)}=39.14 ;{ }^{* * *} P=0.0004$ for the wild-type after KA administration vs neuropsin-KO after KA administration). (h) Representative western blots showing the levels of phosphorylated ErbB4 (pErbB4), total ErbB4 and $\beta$-actin in the hippocampus from wild-type or neuropsin-KO mice $4 \mathrm{~h}$ after PBS or KA administration. (i) Quantitative densitometric analysis of western blots. Ratios for pErbB4/ErbB4 (left) and ErbB4/ $\beta$-actin (right) are shown. The fold change was normalized to PBS in wild-type mice. pErbB4 protein levels are upregulated by seizure activity in wild-type mice (one-way ANOVA, $\mathrm{F}_{(3,22)}=9.601,{ }^{* * *} P=0.0003$ vs PBS) but not in neuropsin-KO mice ( $P=0.9637$ vs PBS). $\beta$-actin served as the loading control. Error bars indicate the SEM. ${ }^{*} P<0.05,{ }^{* *} P<0.01,{ }^{* * *} P<0.001$ and ${ }^{* * * *} P<0.0001$; one-way ANOVA with Turkey's post-hoc test. Numbers inside columns indicate $n$. KA, kainate; KO, knockout; NRG1, neuregulin 1; PBS, phosphate buffered saline; SEM, standard error of the mean.

marker of excitatory neurons (Supplementary Figure 4 and Supplementary Table 2). Consistent with the timing of cFos activation in ErbB4-labeled neurons, the number of parvalbuminpositive interneurons expressing cFos was higher at $4 \mathrm{~h}$ than at $1 \mathrm{~h}$ after KA administration ( $1 \mathrm{~h}$ after KA administration, $1.7 \pm 0.5$ neurons per area; $4 \mathrm{~h}$ after KA administration, $11.9 \pm 1.4$ neurons per area; Mann-Whitney $U$ test, $P=0.0286$; Supplementary Figure 5). These results show that the cFos expression after the onset of seizures occurs later in ErbB4-expressing parvalbuminpositive interneurons $(4 \mathrm{~h})$ than it does in pyramidal neurons $(1 \mathrm{~h})$, and that the timing of expression in parvalbumin-positive interneurons corresponds with the peak of activation of neuropsin after KA injection.

To determine whether the appearance of cFos labeling in ErbB4-positive neurons was mediated by neuropsin, we compared hippocampal tissues from neuropsin-KO and wild-type mice $4 \mathrm{~h}$ after KA administration (Supplementary Figure 6 and Figure 4a1a3). The number of cFos-expressing ErbB4-labeled neurons in neuropsin-KO mice $(5.8 \pm 0.9$ neurons per area) was significantly lower than that in wild-type mice $(17.0 \pm 2.6$ neurons per area; Mann-Whitney $U$ test, $P=0.0286$; Figure 4a3, left panel); however, the number of cFos-positive pyramidal neurons in neuropsin-KO mice (170.9 \pm 8.6 neurons per area) was significantly higher than that in wild-type mice $(42.1 \pm 8.1$ neurons per area; Mann-Whitney $U$ test, $P=0.0286$; Figure $4 a 3$, right panel). The fraction of cFosexpressing pyramidal neurons represented $11.8 \pm 2.5 \%$ (wild-type) and $42.9 \pm 4.5 \%$ (neuropsin-KO) of the total number of pyramidal neurons, whereas the fraction of cFos-expressing ErbB4-positive neurons represented $72.2 \pm 4.4 \%$ (wild-type) and $39 \pm 4.0 \%$ (neuropsin-KO) of the total number of ErbB4-positive neurons. We defined the ratio between the fractions of cFos-labeled pyramidal neurons and cFos-labeled ErbB4-positive neurons as the E/I balance. The $\mathrm{E} / \mathrm{I}$ balance was elevated in neuropsin-KO mice compared with the wild-type mice (Mann-Whitney $U$ test, $P=0.0286$; Figure 4a4). However, the density of ErbB4-positive neurons was not significantly different between the groups (ErbB4-positive neuron numbers per $500000 \mathrm{\mu m}^{3}$ in the CA1 region were $20 \pm 3.6$ (wild-type) and $19.5 \pm 3.3$ (neuropsin-KO); $n=4$ mice each, Mann-Whitney $U$ test, $P=0.8571$ ). These results suggest that neuropsin deficiency impairs the activation of ErbB4positive neurons, resulting in hyperactivity of pyramidal neurons in the stimulated state and breakdown of the E/I balance. Similarly, compared with that in wild-type mice, only half the number of cFos-expressing parvalbumin-positive interneurons (wild-type, $10 \pm 1.2$ neurons per area; neuropsin-KO, $4.8 \pm 1.1$ neurons per area; Mann-Whitney $U$ test, $P=0.0286$; Supplementary Figure 6 and Figure 4b1-b3) and a higher level of E/l balance, defined as the ratio between the fraction of cFos-labeled pyramidal neurons and cFos-labeled parvalbumin-positive interneurons (Mann-Whitney $U$ test, $P=0.0286$; Figure $4 \mathrm{~b} 4$ ), were detected in neuropsin-KO mice. The fraction of cFos-expressing parvalbumin-positive neurons represented $78.8 \pm 7.2 \%$ (wild-type) and $38.3 \pm 3.8 \%$ (neuropsin-KO) of the total number of parvalbumin-positive neurons. The altered E/I balance and lower cFos expression by inhibitory neurons in neuropsin-KO mice were reversed by intracerebroventricular injection of recombinant NRG1 ${ }_{177-246}$ at $3 \mathrm{~h}$ after KA administration (Figures $5 \mathrm{a}-\mathrm{c}$ ). Interestingly, injection of NRG1 ${ }_{177-246}$ significantly reduced seizure severity at $4 \mathrm{~h}$ after KA administration in these mice (two-way ANOVA, $F_{(1,8)}=1.134$, $P=0.0186$; Figure $5 \mathrm{~d}$ ). Taken together, these results indicate that seizure activity activates ErbB4-expressing parvalbumin-positive interneurons via neuropsin-NRG1 signaling.

Hippocampal gamma oscillations are impaired in neuropsin-KO mice

The activity of parvalbumin-positive interneurons is critical for driving gamma oscillations, $3,4,7,40$ and NRG1 increases the power of gamma oscillations via activation of ErbB4. ${ }^{41}$ Because we found that neuropsin contributed to the activation of ErbB4-expressing parvalbumin-positive interneurons, we investigated whether neuropsin is involved in hippocampal gamma activity. The slow $(30-45 \mathrm{~Hz})$ and fast $(65-120 \mathrm{~Hz})$ gamma oscillations in the local field potential were recorded in the hippocampal CA1 region of anesthetized mice. Following a $30 \mathrm{~min}$ baseline recording the mice received a single injection of $\mathrm{KA}\left(25 \mathrm{mg} \mathrm{kg}^{-1}\right.$, i.p.). The power level of slow gamma oscillations in neuropsin-KO mice during baseline recording was similar to that in wild-type mice (530 min before KA administration: wild-type, 6.486 $\pm 0.08910^{-8} \mathrm{~V}^{2}$ / $\mathrm{Hz}$; neuropsin-KO, $6.344 \pm 0.08510^{-8} \mathrm{~V}^{2} / \mathrm{Hz}$; one-way ANOVA, $\left.F_{(3,20)}=0.8335, P=0.5739\right)$; however, it was significantly lower after KA administration (two-way ANOVA, $F_{(3,20)}=6.343, P=0.0034$; Figures $6 \mathrm{a}-\mathrm{c})$. Lateral cerebroventricular injection of recombinant 

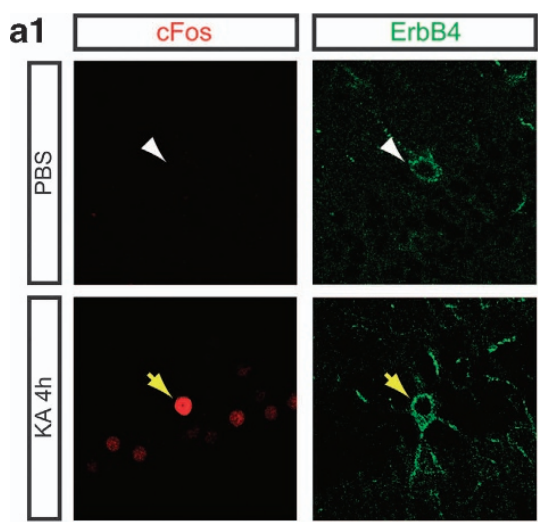

a2
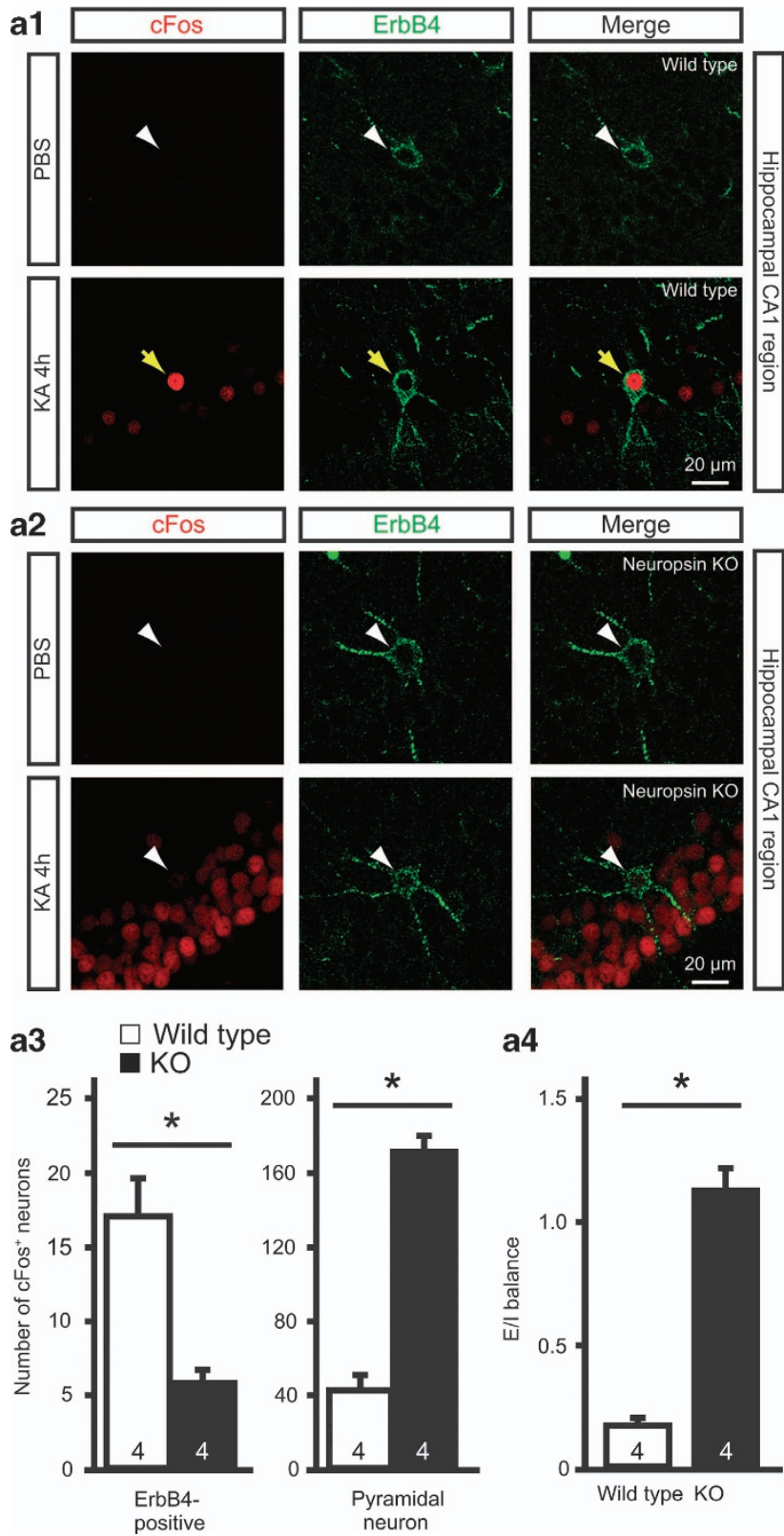

a4

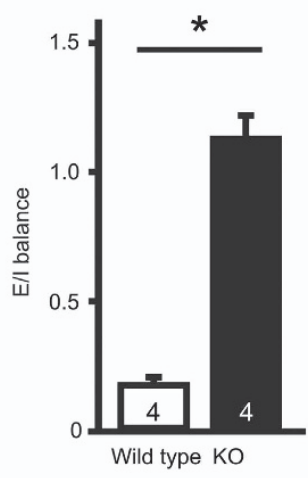

b1
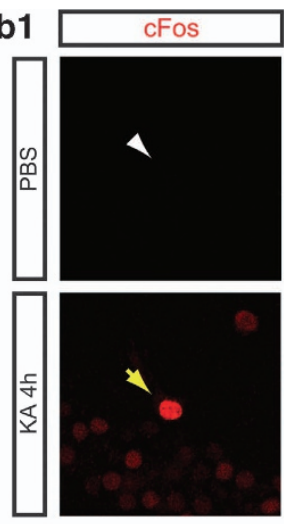

b2
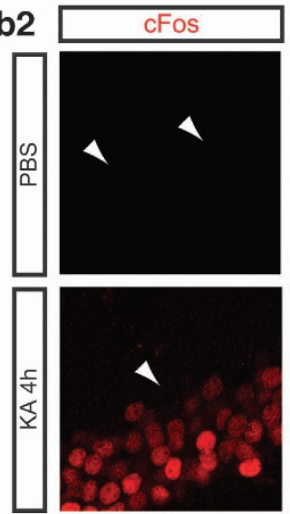

b3
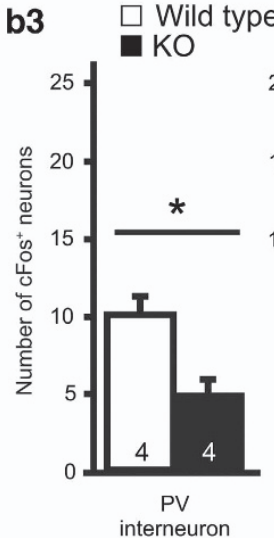
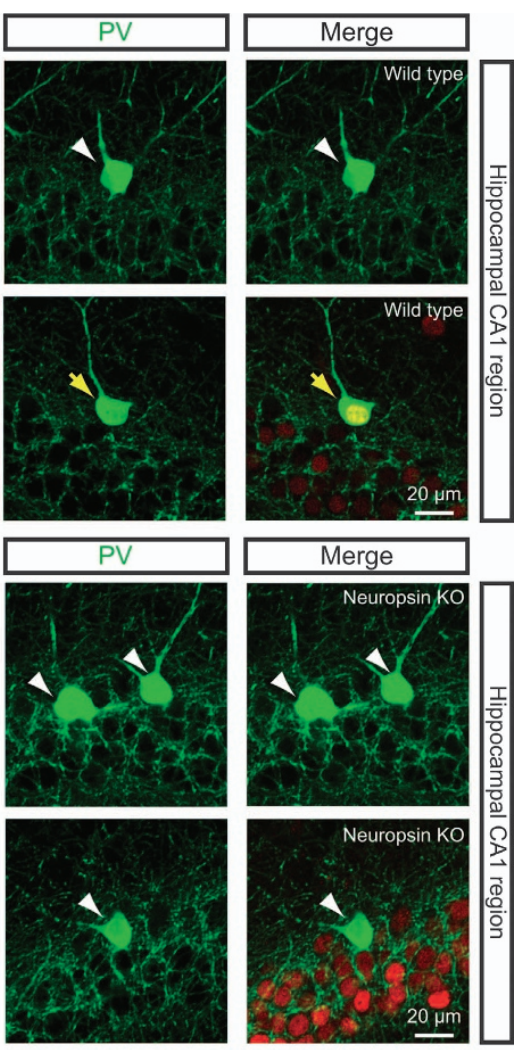

b4
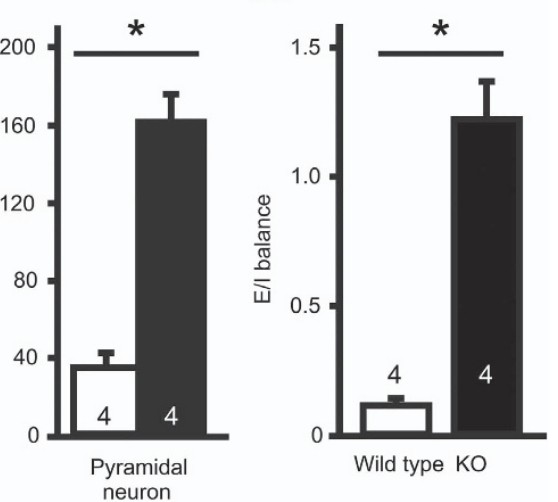

Figure 4. Neuropsin-KO mice show reduced cFos expression in ErbB4-positive neurons and inhibitory activity and enhanced excitatory activity after seizure. (a1, a2) Expression of cFos in ErbB4-positive and pyramidal neurons of wild-type (a1) or neuropsin-KO (a2) mice $4 \mathrm{~h}$ after PBS (upper panel) or KA (lower panel) administration. Fluorescent labeling of the hippocampal CA1 region shows strong cFos immunoreactivity (red) in ErbB4positive neurons (green) in wild-type mice, but only faint staining in neuropsin-KO mice. Yellow arrows indicate ErbB4-positive neurons expressing cFos. White arrowheads indicate ErbB4-positive neurons that do not express cFos. (a3) Quantitative analysis of cFos immunofluorescent labeling of ErbB4-positive and pyramidal neurons of the wild-type (white bars) and neuropsin-KO (black bars) mice shown in a1 and a2. The number of cFosexpressing ErbB4-positive neurons in neuropsin-KO mice was significantly lower than that in wild-type mice (Mann-Whitney $U$ test, ${ }^{*} P=0.0286$ vs wild-type); by contrast, the number of cFos-immunoreactive pyramidal neurons from neuropsin-KO mice was significantly higher than that in wildtype mice (Mann-Whitney $U$ test, ${ }^{*} P=0.0286$ vs wild-type). Data are expressed as the mean and SEM. (a4) E/l balance, defined as the ratio between the fractions of pyramidal neurons and ErbB4-positive neurons expressing cFos, in wild-type (white bar) and neuropsin-KO (black bar) mice. The E/I balance in neuropsin-KO mice was significantly higher than that in wild-type mice (Mann-Whitney $U$ test, ${ }^{*} P=0.0286$ vs wild-type). (b1, b2) Expression of cFos in parvalbumin (PV)-positive interneurons (arrows) and pyramidal neurons in wild-type (b1) or neuropsin-KO (b2) mice $4 \mathrm{~h}$ after PBS (upper panel) or KA (lower panel) administration. Fluorescent labeling of the hippocampal CA1 region shows strong cFos immunoreactivity (red) in parvalbumin-positive interneurons (green) in wild-type mice, but only faint staining in neuropsin-KO mice. Yellow arrows indicate parvalbumin-positive neurons expressing cFos. White arrowheads indicate parvalbumin-positive neurons that do not express cFos. (b3) Quantitative analysis of cFos immunofluorescent labeling in PV-positive interneurons and pyramidal neurons of wild-type (white bars) and neuropsin-KO (black bars) in the mice shown in $\mathbf{b} 1$ and $\mathbf{b} 2$. The number of cFos-expressing parvalbumin-positive interneurons in neuropsin-KO mice was significantly lower than that in wild-type mice (Mann-Whitney $U$ test, ${ }^{*} P=0.0286$ vs wild-type); by contrast, the number of cFosimmunoreactive pyramidal neurons in neuropsin-KO mice was significantly higher than that in wild-type mice (Mann-Whitney $U$ test, ${ }^{*} P=0.0286$ vs wild-type). Data are expressed as the mean and SEM. (b4) E/I balance, defined as the ratio between the fractions of pyramidal neurons and parvalbumin-positive interneurons expressing cFos in wild-type (white bar) and neuropsin-KO (black bar) mice. The E/I balance in neuropsin-KO mice was significantly higher than that in wild-type mice (Mann-Whitney $U$ test, ${ }^{*} P=0.0286$ vs wild-type). Numbers inside columns indicate $n$. $\mathrm{KA}$, kainate; KO, knockout; PBS, phosphate buffered saline; SEM, standard error of the mean. 

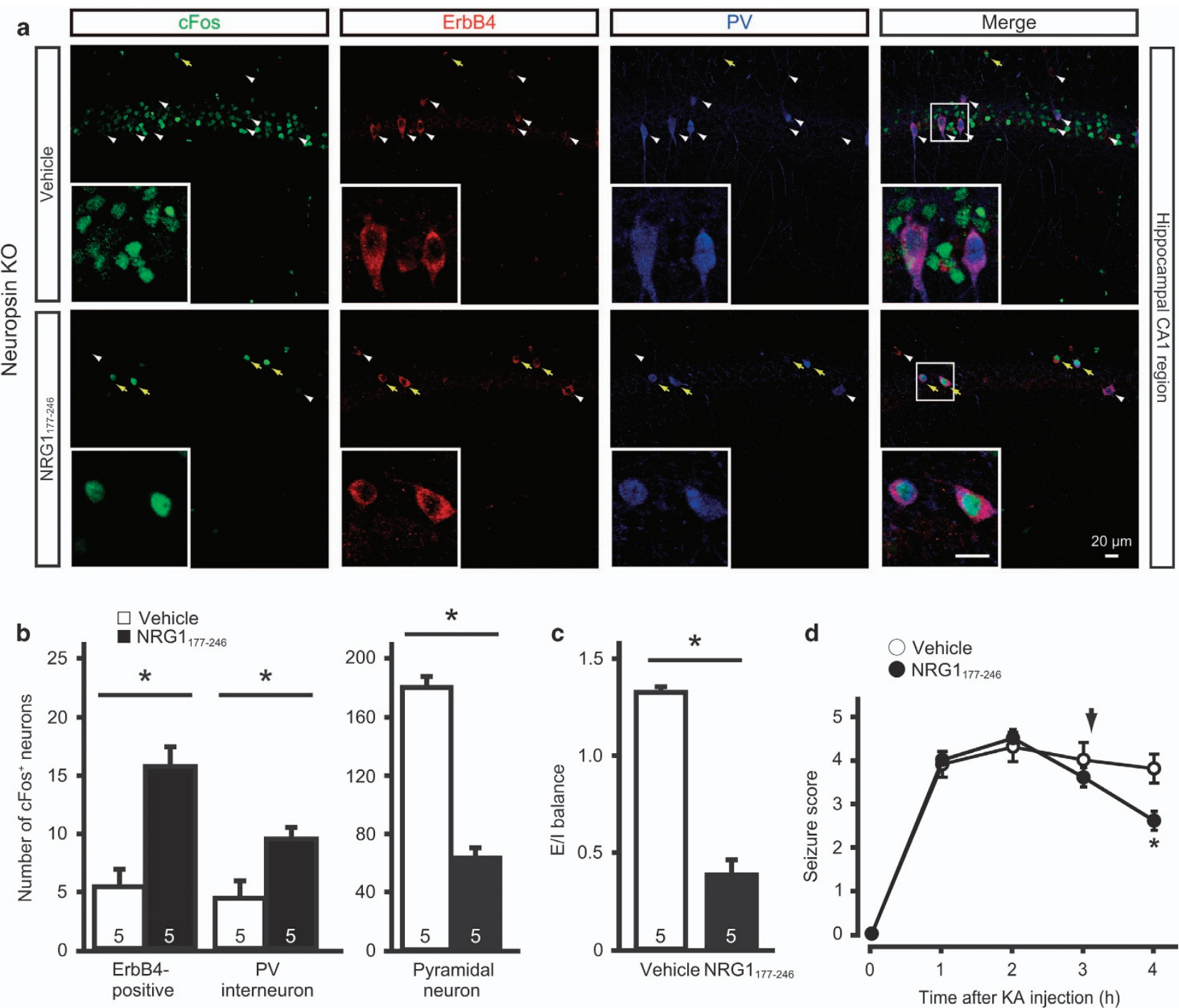

Figure 5. Effect of intracerebroventricular injection of NRG1 $177-246$ on E/I balance and KA-induced seizure in neuropsin-KO mice. (a) Expression of cFos (green) in ErbB4-positive neurons (red), parvalbumin (PV)-positive interneurons (blue) and pyramidal neurons at $4 \mathrm{~h}$ after KA administration in vehicle- (upper panel) or NRG1 $177-246$-injected (lower panel) neuropsin-KO mice. Yellow arrows indicate ErbB4-positive neurons expressing cFos. White arrowheads indicate ErbB4-positive neurons that do not express cFos. Regions inside the boxes are enlarged in the inset images (scale bar, $20 \mu \mathrm{m}$ ). (b) Quantitative analysis of cFos expression in ErbB4-positive neurons, PV-positive interneurons, and pyramidal neurons in the vehicle- (white bars) and NRG1 $1_{177-246}$-injected (black bars) neuropsin-KO mice shown in a. Significantly more ErbB4-positive neurons and parvalbumin-positive interneurons were immunoreactive for cFos in NRG1 ${ }_{177-246}$-injected neuropsin-KO mice than in vehicle-injected mice (Mann-Whitney $U$ test, ${ }^{*} P=0.0286$ vs vehicle); by contrast, the number of cFos-immunoreactive pyramidal neurons in NRG1 ${ }_{177-246}$-injected neuropsin-KO mice was significantly lower than that in vehicle-injected mice (Mann-Whitney $U$ test, ${ }^{*} P=0.0286$ vs vehicle). (c) E/l balance, defined as the ratio between the fractions of pyramidal neurons and parvalbumin-positive interneurons expressing cFos, in vehicle- (white bar) and NRG1 ${ }_{177-246}$-injected (black bar) neuropsin-KO mice. The E/I balance in NRG1 ${ }_{177-246}$-injected neuropsin-KO mice was significantly lower than that in vehicle-injected mice (Mann-Whitney $U$ test, ${ }^{*} P=0.0286$ vs vehicle). Numbers inside the columns indicate $n$. (d) Time course of the seizure score in vehicle- or NRG1 ${ }_{177-246}$-injected neuropsin-KO mice after KA administration. The seizure score for NRG1 $177-246$-injected mice (black circles; $n=5$ mice) was significantly lower than that for vehicle-injected mice (white circles; $n=5$ mice) only at $4 \mathrm{~h}$ after KA administration $\left(\mathrm{F}_{(1,8)}=1.134 ;{ }^{*} P=0.019\right.$; two-way ANOVA with the Sidak post-hoc test). The arrow denotes the point of vehicle or NRG1 ${ }_{177-246}$ injection. Error bars indicate the SEM. E/I balance, excitation-inhibition balance; KA, kainate; KO, knockout; NRG1, neuregulin 1.

NRG1 ${ }_{177-246}$ into neuropsin-KO mice led to complete recovery of the power of slow gamma oscillations to wild-type levels $(P<0.05$ at 45,50 and $60 \mathrm{~min}$, and $P<0.01$ at $55 \mathrm{~min}$ after $\mathrm{KA}$ administration between KO+vehicle and $\mathrm{KO}+\mathrm{NRG} 1_{177-246 ;}$ no significant difference between wild-type+vehicle and $\mathrm{KO}$ + NRG1 177-246; Figures 6a-c). NRG $1_{177-246}$ also increased the power of these oscillations in wild-type mice (Figures $6 a-c)$. The peak frequency was the same for all groups (one-way ANOVA, $F_{(3,20)}=$ $0.6128, P=0.6146$; Figure $6 \mathrm{~d}$ ). Both wild-type and neuropsin-KO mice exhibited fast gamma oscillation of similar power and peak frequency both before and after KA administration (two-way ANOVA, $F_{(3,20)}=1.834, P=0.1735$; Supplementary Figure 7). Lateral cerebroventricular injection of NRG1 $177-246$ increased the power to the same level in both groups of mice (Supplementary Figure 7). Thus, neuropsin-KO mice showed a clear deficit in slow, but not fast, gamma oscillation activity, which was ameliorated by addition of NRG1 comprising the ligand domain for ErbB4. 
$(\mathrm{mV})$
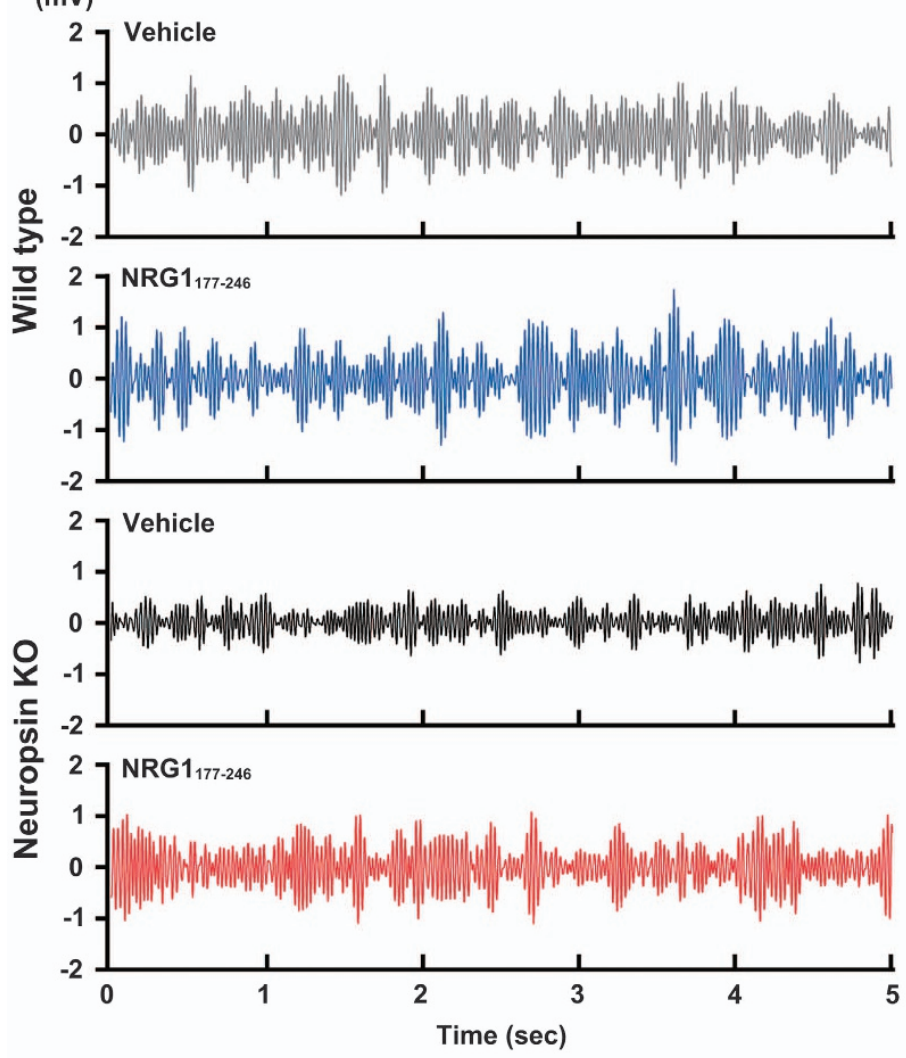

c

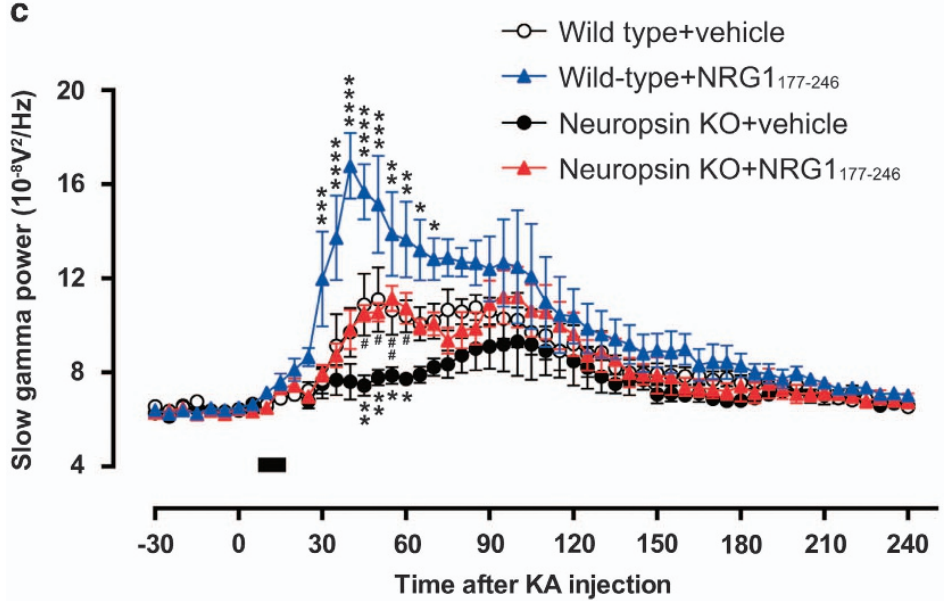

b

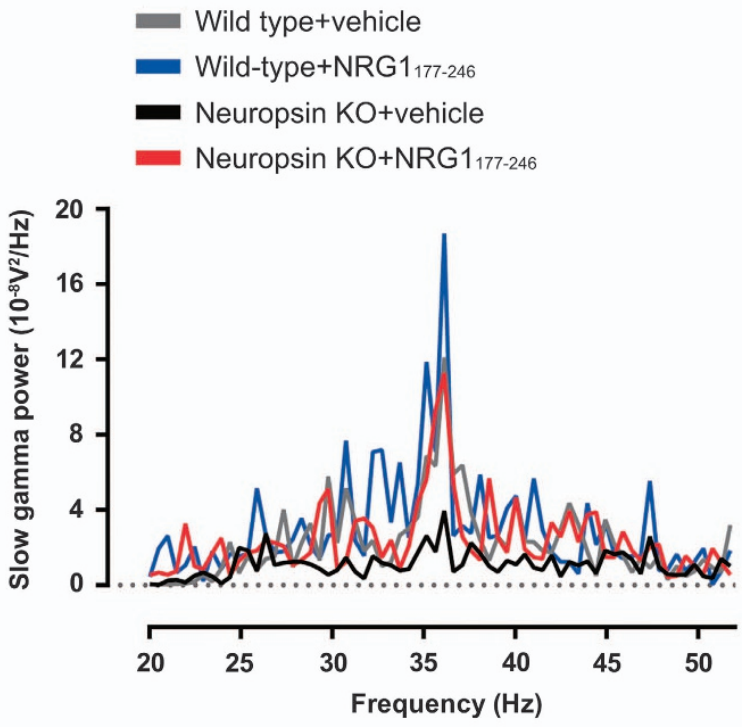

d

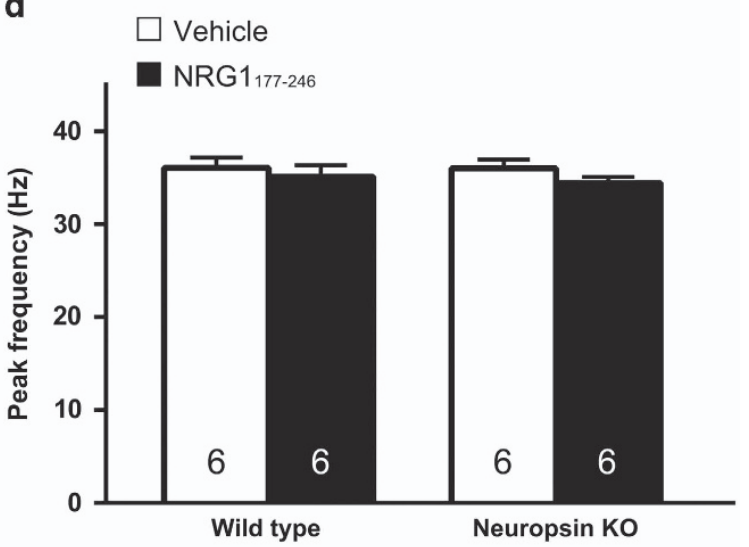

Figure 6. Disrupted slow gamma oscillations in neuropsin-KO mice. (a, b) Representative local field potential traces ( $30-50 \mathrm{~Hz})(\mathbf{a})$ and power spectra (b) of KA-induced slow gamma oscillations in wild-type mice after vehicle (gray) or NRG1 $1_{177-246}$ injection (blue) and in neuropsin-KO mice after vehicle (black) or NRG1 ${ }_{177-246}$ injection (red). (c) Time course for the mean power (and SEM) (30-50 Hz) of KA-induced slow gamma oscillations in wild-type mice after vehicle (white circles; $n=6$ mice) or NRG1 $1_{177-246}$ injection (blue triangles; $n=6$ mice) and in neuropsin-KO mice after vehicle (black circles; $n=6$ mice) or NRG $1_{177-246}$ injection (red triangles; $n=6$ mice). The power of the slow gamma oscillations in the CA1 region in neuropsin-KO mice was less than that in wild-type mice, but recovered after injection of $N R G 1_{177-246}\left(F_{(3,20)}=6.343, P=0.0034\right.$; two-way ANOVA). Significant differences between wild-type and neuropsin-KO mice were observed at $45-60$ min after vehicle injection (45 min, ${ }^{* *} P=0.0044 ; 50 \mathrm{~min},{ }^{*} P=0.0067 ; 55 \mathrm{~min},{ }^{*} P=0.0347 ; 60 \mathrm{~min},{ }^{*} P=0.0459$; two-way ANOVA with the Sidak post-hoc test). Significant differences between wild-type mice were seen from 30 to $70 \mathrm{~min}$ after injection of vehicle or NRG $1_{177-246}(30 \mathrm{~min}$, ***P=0.0002; 35 min, ${ }^{* * *} P<0.0001 ; 40 \mathrm{~min},{ }^{* * *} P<0.0001 ; 45 \mathrm{~min},{ }^{* * * *} P<0.0001 ; 50 \mathrm{~min},{ }^{* * *} P=0.0005 ; 55 \mathrm{~min},{ }^{* *} P=0.0082 ; 60 \mathrm{~min},{ }^{* *} P=0.0082 ; 65 \mathrm{~min}$, ${ }^{*} P=0.0117 ; 70 \mathrm{~min},{ }^{*} P=0.0462$; two-way ANOVA with the Sidak post-hoc test). There were significant differences between neuropsin-KO mice at 45-60 min post-injection with vehicle or NRG1 $177-246$ (45 min, ${ }^{\#} P=0.0145 ; 50 \mathrm{~min},{ }^{\#} P=0.0329 ; 55 \mathrm{~min},{ }^{\# \#} P=0.0075 ; 60 \mathrm{~min},{ }^{\#} P=0.0183$; twoway ANOVA with the Sidak post-hoc test). NRG1 $177-246$ or vehicle was injected during the time period indicated by the bar. (d) Bar graph showing the mean (and SEM) peak frequency of KA-induced slow gamma oscillations in wild-type mice and neuropsin-KO mice after injection of vehicle (white bar) or NRG1 $177-246$ (black bar). No difference in the peak frequency of slow gamma oscillations was detected between the groups $\left(\mathrm{F}_{(3,20)}=0.6128, P=0.6146\right.$; one-way ANOVA with Tukey's post-hoc test). Numbers inside columns indicate $n$. KA, kainate; KO, knockout; NRG1, neuregulin 1; SEM, standard error of the mean. 


\section{DISCUSSION}

The main findings of the present study are that neuropsin is involved in the generation of slow gamma oscillations and in the delayed seizure-related activation of ErbB4-expressing parvalbumin-positive interneurons, which regulate the hippocampal E/I balance in vivo. The $\mathrm{E} / \mathrm{I}$ balance in neuropsin-KO mice, in which NRG1-ErbB4 signaling was considerably impaired, was also disturbed and accompanied by hypoactivity of parvalbuminexpressing interneurons and pyramidal neuron hyperexcitability. The power of the slow gamma oscillations was reduced, whereas their peak frequency was unchanged. The E/I imbalance and reduced gamma power were restored by application of NRG1 $1_{177-}$ 246, a synthetic functional peptide derived from NRG1 but lacking the heparin-binding domain. These results suggest that the neuropsin-NRG1 signaling system is essential to maintain the balance of network excitability and the magnitude of slow gamma oscillations.

Single parvalbumin-positive GABAergic interneurons innervate about a thousand pyramidal neurons. ${ }^{42}$ This central inhibitory control on pyramidal neurons is thought to produce rhythmic oscillatory activity, ${ }^{3,4}$ and to contribute to brain cognition and memory formation. ${ }^{43,44}$ Although accumulating evidence suggests that $\mathrm{E} / \mathrm{I}$ networks are engaged in the processing and storage of information, ${ }^{1}$ the mechanism of activity-dependent regulation of GABAergic interneurons, of which most are parvalbumin-positive, is not well understood. A previous study reported that the expression of cFos in excitatory neurons precedes its expression in inhibitory interneurons after the onset of behavioral seizures in a mouse model of epilepsy. ${ }^{45}$ Consistently, we observed that parvalbumin-positive GABAergic interneurons exhibited strong cFos immunoreactivity $4 \mathrm{~h}$ after KA administration, but only faint immunoreactivity at earlier time points. By contrast, neuropsin-KO mice exhibited a larger number of cFos-expressing pyramidal neurons and fewer cFos-expressing parvalbumin-positive interneurons than wild-type mice, suggesting that cFos expression in parvalbumin-positive interneurons depends on neural activitydependent activation of neuropsin. We also found that neuropsinNRG1-ErbB4 signaling was enhanced in parallel with cFos expression in parvalbumin-positive interneurons. Phosphorylation of ErbB4, induced by NRG1 binding, increases the excitability of parvalbumin-positive interneurons, but not pyramidal neurons, by regulating Kv1.1, a voltage-gated potassium channel on parvalbumin-positive interneurons; ${ }^{39,46}$ it also drives GABA release from parvalbumin-expressing interneurons. ${ }^{47}$ Therefore, parvalbumin-expressing interneuron activity may be regulated by neuropsin-NRG1 signaling at the excitatory synapse. This hypothesis is supported by our electrophysiological experiments which showed impaired GABAergic transmission in neuropsin-KO mice and its rescue by application of NRG1 $1_{177-246}$. Therefore, neuropsinNRG1-ErbB4 signaling may be one of the molecular mechanisms activating parvalbumin-expressing interneurons during seizures, although it remains to be determined whether these two events are causally related.

Gamma oscillations are thought to be involved in higher cognitive processes, such as working memory, and to be associated with phase-locked rhythmic activity of basket cells expressing parvalbumin. ${ }^{48}$ Indeed, a recent optogenetic study showed that rhythmic stimulation of parvalbumin-expressing interneurons increases oscillation activity at the gamma frequency, but not at other frequencies. ${ }^{3}$ Previous studies reported that NRG1 increases gamma oscillation power in the hippocampus and prefrontal cortex through activation of ErbB4 on parvalbuminexpressing interneurons, though the power is reduced in Erbb4null mutant slices without any defect in frequency; ${ }^{41,49}$ our present study is consistent with these observations. Overall, these results implicate NRG1-ErbB4 signaling in the molecular mechanisms that underlie the magnitude of gamma oscillations. However, they do not rule out the possibility that NRG1 regulates gamma frequency, because hippocampal slices from transgenic mice overexpressing NRG1 exhibited a reduced frequency of carbacholinduced gamma oscillations. ${ }^{50}$ In the present study, neuropsin-KO mice had reduced gamma power but normal peak frequency; injection of NRG1 $1_{177-246}$ restored the power impairment to wildtype levels and was accompanied by a slight, but statistically insignificant decrease in peak frequency. These results indicate that neuropsin modulates gamma power through NRG1 signaling, although the actuation of NRG1 signaling by an additional system other than neuropsin proteolysis cannot be excluded. Gamma oscillations correspond to synchronous inhibitory post-synaptic potentials arising from fast-spiking interneurons. ${ }^{48}$ Consistent with this finding, NRG1 enhances the synchrony between firing pairs of fast-spiking interneurons and pyramidal neurons by activating ErbB4. ${ }^{49}$ Hence, ablation of neuropsin-NRG1 signaling may impair the synchronous activity of neuronal assemblies, contributing to cognitive impairment in several psychiatric diseases such as schizophrenia. ${ }^{51}$ As such, the impairment of spatial working memory observed in neuropsin-KO mice has been proposed to be due to a dysfunction of gamma oscillations mediated by parvalbumin-expressing interneurons; ${ }^{15}$ this idea is supported by the finding that functional removal of parvalbumin-expressing interneurons impairs spatial working memory. ${ }^{52}$

We found that neuropsin-KO mice exhibit pyramidal neuron hyperexcitability due to reduced parvalbumin-expressing interneuron activity, although it is not clear whether the effects of neuropsin on cFos labeling reflect changes in synaptic and neuronal activity. Disturbance of the $\mathrm{E} / \mathrm{l}$ balance underlies the pathogenesis of several cognitive disorders, including epilepsy, ${ }^{53}$ autism $^{54}$ and schizophrenia. ${ }^{7,55}$ Also, many studies show that disrupted GABAergic interneuron signaling and reduced inhibitory activity are linked to these pathological conditions. ${ }^{9,56,57}$ Increasing evidence shows that abnormalities in brain extracellular matrix components, including proteoglycans, likely contribute to some aspects of pathophysiologies involving synaptic dysfunction and altered GABAergic, glutamatergic and dopaminergic transmission. ${ }^{58,59}$ Interestingly, previous studies show that Nrg1 and Erbb4 mutant mice have schizophrenic-like deficits such as hyperactivity, impaired prepulse inhibition and latent inhibition, reduced working memory, cognitive deficits and social withdrawal. ${ }^{60-71}$ Similarly, neuropsin-KO mice exhibit relevant behavioral deficits. ${ }^{15,72}$ Although the expression levels of the NRG1 transcript and NRG1 protein in patients with schizophrenia remain controversial, serum levels of soluble NRG1 are reportedly low in these patients, ${ }^{73}$ suggesting impaired release of NRG1. Altogether, these results suggest that mutations in the genes encoding neuropsin or NRG1, which inhibit the production of the ligand moiety or generate a functionally impaired ligand, will disrupt NRG1-ErbB4 signaling and alter the E/I balance, possibly leading to the cognitive dysfunctions observed in bipolar and schizophrenic syndromes.

\section{CONFLICT OF INTEREST}

The authors declare no conflict of interest.

\section{ACKNOWLEDGMENTS}

This work was supported by JSPS KAKENHI (No. 24500439 and JP15K06784 to HT and No. 25290022 to SS) from the Ministry of Education, Culture, Sports, Science and Technology (MEXT) of Japan, and the MEXT-Supported Programs for the Strategic Priority Budget for 'Program for Promotion of Researches toward Creation of Humanophilic Science and Technology'. We thank Professor Yuji Ikegaya (The University of Tokyo) for assistance in interpreting the electrophysiological results. 


\section{REFERENCES}

1 Froemke RC. Plasticity of cortical excitatory-inhibitory balance. Annu Rev Neurosci 2015; 38: 195-219.

2 Klausberger T, Somogyi P. Neuronal diversity and temporal dynamics: the unity of hippocampal circuit operations. Science 2008; 321: 53-57.

3 Sohal VS, Zhang F, Yizhar O, Deisseroth K. Parvalbumin neurons and gamma rhythms enhance cortical circuit performance. Nature 2009; 459: 698-702.

4 Cardin JA, Carlen M, Meletis K, Knoblich U, Zhang F, Deisseroth K et al. Driving fast-spiking cells induces gamma rhythm and controls sensory responses. Nature 2009; 459: 663-667.

5 Wulff P, Ponomarenko AA, Bartos M, Korotkova TM, Fuchs EC, Bahner F et al. Hippocampal theta rhythm and its coupling with gamma oscillations require fast inhibition onto parvalbumin-positive interneurons. Proc Natl Acad Sci USA 2009; 106: 3561-3566.

6 Craig MT, McBain CJ. Fast gamma oscillations are generated intrinsically in CA1 without the involvement of fast-spiking basket cells. J Neurosci 2015; 35: 3616-3624.

7 Lewis DA, Curley AA, Glausier JR, Volk DW. Cortical parvalbumin interneurons and cognitive dysfunction in schizophrenia. Trends Neurosci 2012; 35: 57-67.

8 Ogiwara I, Miyamoto H, Morita N, Atapour N, Mazaki E, Inoue I et al. Nav1.1 localizes to axons of parvalbumin-positive inhibitory interneurons: a circuit basis for epileptic seizures in mice carrying an Scn1a gene mutation. J Neurosci 2007; 27: 5903-5914.

9 Lewis DA, Hashimoto T, Volk DW. Cortical inhibitory neurons and schizophrenia. Nat Rev Neurosci 2005; 6: 312-324.

10 Tamura H, Ishikawa Y, Shiosaka S. Does extracellular proteolysis control mammalian cognition? Rev Neurosci 2013; 24: 365-374.

11 Dityatev A, Fellin T. Extracellular matrix in plasticity and epileptogenesis. Neuron Glia Biol 2008; 4: 235-247.

12 Shiosaka S, Ishikawa Y. Neuropsin-a possible modulator of synaptic plasticity. J Chem Neuroanat 2011; 42: 24-29.

13 Sonderegger P, Matsumoto-Miyai K. Activity-controlled proteolytic cleavage at the synapse. Trends Neurosci 2014; 37: 413-423.

14 Pang PT, Teng HK, Zaitsev E, Woo NT, Sakata K, Zhen S et al. Cleavage of proBDNF by $\mathrm{tPA}$ /plasmin is essential for long-term hippocampal plasticity. Science 2004; 306: 487-491.

15 Tamura H, Ishikawa Y, Hino N, Maeda M, Yoshida S, Kaku S et al. Neuropsin is essential for early processes of memory acquisition and Schaffer collateral longterm potentiation in adult mouse hippocampus in vivo. J Physiol 2006; 570: 541-551.

16 Nagy V, Bozdagi O, Matynia A, Balcerzyk M, Okulski P, Dzwonek J et al. Matrix metalloproteinase- 9 is required for hippocampal late-phase long-term potentiation and memory. J Neurosci 2006; 26: 1923-1934.

17 Matsumoto-Miyai K, Sokolowska E, Zurlinden A, Gee CE, Luscher D, Hettwer S et al. Coincident pre- and postsynaptic activation induces dendritic filopodia via neurotrypsin-dependent agrin cleavage. Cell 2009; 136: 1161-1171.

18 Mizoguchi H, Nakade J, Tachibana M, Ibi D, Someya E, Koike H et al. Matrix metalloproteinase- 9 contributes to kindled seizure development in pentylenetetrazole-treated mice by converting pro-BDNF to mature BDNF in the hippocampus. J Neurosci 2011; 31: 12963-12971.

19 Smith AC, Kupchik YM, Scofield MD, Gipson CD, Wiggins A, Thomas CA et al. Synaptic plasticity mediating cocaine relapse requires matrix metalloproteinases. Nat Neurosci 2014; 17: 1655-1657.

20 Chen ZL, Yoshida S, Kato K, Momota Y, Suzuki J, Tanaka T et al. Expression and activity-dependent changes of a novel limbic-serine protease gene in the hippocampus. J Neurosci 1995; 15: 5088-5097.

21 Shimizu C, Yoshida S, Shibata M, Kato K, Momota Y, Matsumoto K et al. Characterization of recombinant and brain neuropsin, a plasticity-related serine protease. J Biol Chem 1998; 273: 11189-11196.

22 Matsumoto-Miyai K, Ninomiya A, Yamasaki H, Tamura H, Nakamura Y, Shiosaka S. NMDA-dependent proteolysis of presynaptic adhesion molecule L1 in the hippocampus by neuropsin. J Neurosci 2003; 23: 7727-7736.

23 Davies B, Kearns IR, Ure J, Davies CH, Lathe R. Loss of hippocampal serine protease BSP1/neuropsin predisposes to global seizure activity. J Neurosci 2001; 21: 6993-7000.

24 Attwood BK, Bourgognon JM, Patel S, Mucha M, Schiavon E, Skrzypiec AE et al. Neuropsin cleaves EphB2 in the amygdala to control anxiety. Nature 2011; 473: 372-375.

25 Izumi A, lijima Y, Noguchi H, Numakawa T, Okada T, Hori H et al. Genetic variations of human neuropsin gene and psychiatric disorders: polymorphism screening and possible association with bipolar disorder and cognitive functions. Neuropsychopharmacology 2008; 33: 3237-3245.

26 Tamura H, Kawata M, Hamaguchi S, Ishikawa Y, Shiosaka S. Processing of neuregulin- 1 by neuropsin regulates GABAergic neuron to control neural plasticity of the mouse hippocampus. J Neurosci 2012; 32: 12657-12672.
27 Mei L, Xiong WC. Neuregulin 1 in neural development, synaptic plasticity and schizophrenia. Nat Rev Neurosci 2008; 9: 437-452.

28 Liu X, Bates R, Yin DM, Shen C, Wang F, Su N et al. Specific regulation of NRG1 isoform expression by neuronal activity. J Neurosci 2011; 31: 8491-8501.

29 Vullhorst D, Neddens J, Karavanova I, Tricoire L, Petralia RS, McBain CJ et al. Selective expression of ErbB4 in interneurons, but not pyramidal cells, of the rodent hippocampus. J Neurosci 2009; 29: 12255-12264.

30 Hirata A, Yoshida S, Inoue N, Matsumoto-Miyai K, Ninomiya A, Taniguchi M et al. Abnormalities of synapses and neurons in the hippocampus of neuropsindeficient mice. Mol Cell Neurosci 2001; 17: 600-610.

31 Sperk G, Lassmann H, Baran H, Kish SJ, Seitelberger F, Hornykiewicz O. Kainic acid induced seizures: neurochemical and histopathological changes. Neuroscience 1983; 10: 1301-1315.

32 Racine RJ, Gartner JG, Burnham WM. Epileptiform activity and neural plasticity in limbic structures. Brain Res 1972; 47: 262-268.

33 Momota Y, Yoshida S, Ito J, Shibata M, Kato K, Sakurai K et al. Blockade of neuropsin, a serine protease, ameliorates kindling epilepsy. Eur J Neurosci 1998; 10: 760-764.

34 Tamura H, Ng DC, Tokuda T, Naoki H, Nakagawa T, Mizuno T et al. One-chip sensing device (biomedical photonic LSI) enabled to assess hippocampal steep and gradual up-regulated proteolytic activities. J Neurosci Methods 2008; 173: 114-120.

35 Chintawar S, Hourez R, Ravella A, Gall D, Orduz D, Rai M et al. Grafting neural precursor cells promotes functional recovery in an SCA1 mouse model. $J$ Neurosci 2009; 29: 13126-13135.

36 Tan GH, Liu YY, Hu XL, Yin DM, Mei L, Xiong ZQ. Neuregulin 1 represses limbic epileptogenesis through ErbB4 in parvalbumin-expressing interneurons. Nat Neurosci 2011; 15: 258-266.

37 Watt HL, Kumar U. Colocalization of somatostatin receptors and epidermal growth factor receptors in breast cancer cells. Cancer Cell Int 2006; 6: 5.

38 Loeb JA, Fischbach GD. ARIA can be released from extracellular matrix through cleavage of a heparin-binding domain. J Cell Biol 1995; 130: 127-135.

39 Li KX, Lu YM, Xu ZH, Zhang J, Zhu JM, Zhang JM et al. Neuregulin 1 regulates excitability of fast-spiking neurons through Kv1.1 and acts in epilepsy. Nat Neurosci 2012; 15: 267-273.

40 Yizhar O, Fenno LE, Prigge M, Schneider F, Davidson TJ, O'Shea DJ et al. Neocortical excitation/inhibition balance in information processing and social dysfunction. Nature 2011; 477: 171-178.

41 Fisahn A, Neddens J, Yan L, Buonanno A. Neuregulin-1 modulates hippocampal gamma oscillations: implications for schizophrenia. Cereb Cortex 2009; 19: 612-618.

42 Halasy K, Buhl EH, Lorinczi Z, Tamas G, Somogyi P. Synaptic target selectivity and input of GABAergic basket and bistratified interneurons in the CA1 area of the rat hippocampus. Hippocampus 1996; 6: 306-329.

43 Hensch TK. Critical period plasticity in local cortical circuits. Nat Rev Neurosci 2005; 6: 877-888.

44 Donato F, Rompani SB, Caroni P. Parvalbumin-expressing basket-cell network plasticity induced by experience regulates adult learning. Nature 2013; 504: 272-276.

45 Peng Z, Houser CR. Temporal patterns of fos expression in the dentate gyrus after spontaneous seizures in a mouse model of temporal lobe epilepsy. $J$ Neurosci 2005; 25: 7210-7220.

46 Chen YJ, Zhang M, Yin DM, Wen L, Ting A, Wang P et al. ErbB4 in parvalbuminpositive interneurons is critical for neuregulin 1 regulation of long-term potentiation. Proc Natl Acad Sci USA 2010; 107: 21818-21823.

47 Woo RS, Li XM, Tao Y, Carpenter-Hyland E, Huang YZ, Weber J et al. Neuregulin-1 enhances depolarization-induced GABA release. Neuron 2007; 54: 599-610.

48 Buzsaki G, Wang XJ. Mechanisms of gamma oscillations. Annu Rev Neurosci 2012; 35: 203-225.

49 Hou XJ, Ni KM, Yang JM, Li XM. Neuregulin 1/ErbB4 enhances synchronized oscillations of prefrontal cortex neurons via inhibitory synapses. Neuroscience 2014; 261: 107-117.

50 Deakin IH, Nissen W, Law AJ, Lane T, Kanso R, Schwab MH et al. Transgenic overexpression of the type I isoform of neuregulin 1 affects working memory and hippocampal oscillations but not long-term potentiation. Cereb Cortex 2012; 22: 1520-1529.

51 Sigurdsson T, Stark KL, Karayiorgou M, Gogos JA, Gordon JA. Impaired hippocampal-prefrontal synchrony in a genetic mouse model of schizophrenia. Nature 2010; 464: 763-767.

52 Murray AJ, Sauer JF, Riedel G, McClure C, Ansel L, Cheyne L et al. Parvalbuminpositive CA1 interneurons are required for spatial working but not for reference memory. Nat Neurosci 2011; 14: 297-299.

53 Cossart R, Bernard C, Ben-Ari Y. Multiple facets of GABAergic neurons and synapses: multiple fates of GABA signalling in epilepsies. Trends Neurosci 2005; 28: 108-115. 
54 Rubenstein JL, Merzenich MM. Model of autism: increased ratio of excitation/ inhibition in key neural systems. Genes Brain Behav 2003; 2: 255-267.

55 Wassef A, Baker J, Kochan LD. GABA and schizophrenia: a review of basic science and clinical studies. J Clin Psychopharmacol 2003; 23: 601-640.

56 Ramamoorthi K, Lin Y. The contribution of GABAergic dysfunction to neurodevelopmental disorders. Trends Mol Med 2011; 17: 452-462.

57 Levitt P, Eagleson KL, Powell EM. Regulation of neocortical interneuron development and the implications for neurodevelopmental disorders. Trends Neurosci 2004; 27: 400-406.

58 Berretta S. Extracellular matrix abnormalities in schizophrenia. Neuropharmacology 2012; 62: 1584-1597.

59 Berretta S, Pantazopoulos H, Markota M, Brown C, Batzianouli ET. Losing the sugar coating: potential impact of perineuronal net abnormalities on interneurons in schizophrenia. Schizophr Res 2015; 167: 18-27.

60 Boucher AA, Hunt GE, Karl T, Micheau J, McGregor IS, Arnold JC. Heterozygous neuregulin 1 mice display greater baseline and Delta(9)-tetrahydrocannabinolinduced c-Fos expression. Neuroscience 2007; 149: 861-870.

61 Chen YJ, Johnson MA, Lieberman MD, Goodchild RE, Schobel S, Lewandowski N et al. Type III neuregulin-1 is required for normal sensorimotor gating, memoryrelated behaviors, and corticostriatal circuit components. J Neurosci 2008; 28: 6872-6883.

62 Duffy L, Cappas E, Lai D, Boucher AA, Karl T. Cognition in transmembrane domain neuregulin 1 mutant mice. Neuroscience 2010; 170: 800-807.

63 Duffy L, Cappas E, Scimone A, Schofield PR, Karl T. Behavioral profile of a heterozygous mutant mouse model for EGF-like domain neuregulin 1. Behav Neurosci 2008; 122: 748-759.

64 Ehrlichman RS, Luminais SN, White SL, Rudnick ND, Ma N, Dow HC et al. Neuregulin 1 transgenic mice display reduced mismatch negativity, contextual fear conditioning and social interactions. Brain Res 2009; 1294: 116-127.

65 Gerlai R, Pisacane P, Erickson S. Heregulin, but not ErbB2 or ErbB3, heterozygous mutant mice exhibit hyperactivity in multiple behavioral tasks. Behav Brain Res 2000; 109: 219-227.

66 Karl T, Duffy L, Scimone A, Harvey RP, Schofield PR. Altered motor activity, exploration and anxiety in heterozygous neuregulin 1 mutant mice: implications for understanding schizophrenia. Genes Brain Behav 2007; 6: 677-687.
67 Moy SS, Ghashghaei HT, Nonneman RJ, Weimer JM, Yokota Y, Lee D et al. Deficient NRG1-ERBB signaling alters social approach: relevance to genetic mouse models of schizophrenia. J Neurodev Disord 2009; 1: 302-312.

68 O'Tuathaigh CM, O'Sullivan GJ, Kinsella A, Harvey RP, Tighe O, Croke DT et al. Sexually dimorphic changes in the exploratory and habituation profiles of heterozygous neuregulin-1 knockout mice. Neuroreport 2006; 17: 79-83.

69 O'Tuathaigh CM, O'Connor AM, O'Sullivan GJ, Lai D, Harvey R, Croke DT et al. Disruption to social dyadic interactions but not emotional/anxiety-related behaviour in mice with heterozygous 'knockout' of the schizophrenia risk gene neuregulin-1. Prog Neuropsychopharmacol Biol Psychiatry 2008; 32: 462-466.

70 O'Tuathaigh CM, Harte M, O'Leary C, O'Sullivan GJ, Blau C, Lai D et al. Schizophrenia-related endophenotypes in heterozygous neuregulin-1 'knockout' mice. Eur J Neurosci 2010; 31: 349-358.

71 Rimer M, Barrett DW, Maldonado MA, Vock VM, Gonzalez-Lima F. Neuregulin-1 immunoglobulin-like domain mutant mice: clozapine sensitivity and impaired latent inhibition. Neuroreport 2005; 16: 271-275.

72 Horii Y, Yamasaki N, Miyakawa T, Shiosaka S. Increased anxiety-like behavior in neuropsin (kallikrein-related peptidase 8) gene-deficient mice. Behav Neurosci 2008; 122: 498-504.

73 Shibuya M, Komi E, Wang R, Kato T, Watanabe Y, Sakai M et al. Measurement and comparison of serum neuregulin 1 immunoreactivity in control subjects and patients with schizophrenia: an influence of its genetic polymorphism. J Neural Transm 2010; 117: 887-895.

(i) This work is licensed under a Creative Commons Attribution 4.0 International License. The images or other third party material in this article are included in the article's Creative Commons license, unless indicated otherwise in the credit line; if the material is not included under the Creative Commons license, users will need to obtain permission from the license holder to reproduce the material. To view a copy of this license, visit http://creativecommons.org/licenses/ by $/ 4.0 /$

(c) The Author(s) 2017

Supplementary Information accompanies the paper on the Translational Psychiatry website (http://www.nature.com/tp) 